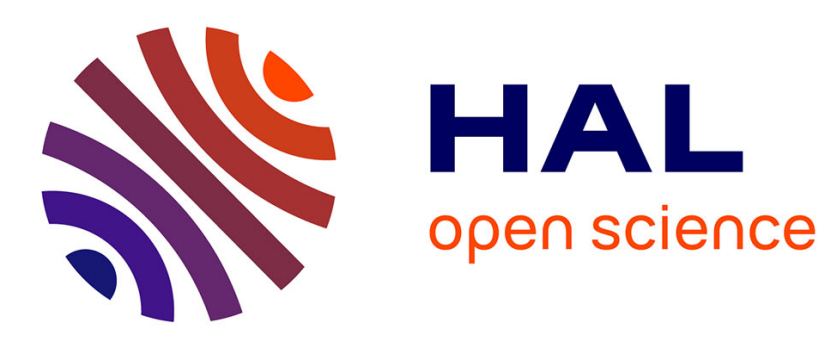

\title{
Platinum-Catalyzed Ethylene Hydroamination with Aniline: Synthesis, Characterization, and Studies of Intermediates
}

Pavel Dub, Mireia Rodriguez-Zubiri, Jean-Claude Daran, Jean-Jacques Brunet, Rinaldo Poli

\section{To cite this version:}

Pavel Dub, Mireia Rodriguez-Zubiri, Jean-Claude Daran, Jean-Jacques Brunet, Rinaldo Poli. Platinum-Catalyzed Ethylene Hydroamination with Aniline: Synthesis, Characterization, and Studies of Intermediates. Organometallics, 2009, 28 (16), pp.4764-4777. 10.1021/om9002494 . hal-03143329

\author{
HAL Id: hal-03143329 \\ https://hal.science/hal-03143329
}

Submitted on 29 Mar 2021

HAL is a multi-disciplinary open access archive for the deposit and dissemination of scientific research documents, whether they are published or not. The documents may come from teaching and research institutions in France or abroad, or from public or private research centers.
L'archive ouverte pluridisciplinaire HAL, est destinée au dépôt et à la diffusion de documents scientifiques de niveau recherche, publiés ou non, émanant des établissements d'enseignement et de recherche français ou étrangers, des laboratoires publics ou privés. 


\title{
Platinum-catalyzed ethylene hydroamination with aniline: Synthesis, Characterization and Studies of Intermediates
}

\author{
Pavel A. Dub, ${ }^{\mathrm{a}, \mathrm{b}}$ Mireia Rodriguez-Zubiri, ${ }^{\mathrm{a}}$ Jean-Claude Daran, ${ }^{\mathrm{a}}$ \\ Jean-Jacques Brunet ${ }^{\mathrm{a}}$ and Rinaldo Poli*,a,c
}

${ }^{a}$ CNRS; LCC (Laboratoire de Chimie de Coordination); 205, route de Narbonne ; Université de Toulouse; UPS, INP; F-31077 Toulouse, France; Fax: (+) 33-561553003; E-mail: poli@lcctoulouse.fr

${ }^{b}$ A. N. Nesmeyanov Institute of Organoelement Compounds, Russian Academy of Sciences, Vavilov Street 26, 119991 Moscow, Russia

${ }^{c}$ Institut Universitaire de France, 103, bd Saint-Michel, 75005 Paris, France 


\section{Summary}

Starting from either $\mathrm{K}_{2} \mathrm{PtCl}_{4}$ or $\mathrm{K}\left[\mathrm{PtCl}_{3}\left(\mathrm{C}_{2} \mathrm{H}_{4}\right)\right] \cdot \mathrm{H}_{2} \mathrm{O}$ (Zeise's salt), complexes $\left(n \mathrm{Bu}_{4} \mathrm{P}\right)_{2}\left[\mathrm{PtBr}_{4}\right](\mathbf{1}), n \mathrm{Bu}_{4} \mathrm{P}\left[\mathrm{PtBr}_{3}\left(\mathrm{C}_{2} \mathrm{H}_{4}\right)\right](\mathbf{2}), n \mathrm{Bu}_{4} \mathrm{P}\left[\mathrm{PtBr}_{3}\left(\mathrm{PhNH}_{2}\right)\right](\mathbf{3})$, trans- $\left[\mathrm{PtBr}_{2}\left(\mathrm{C}_{2} \mathrm{H}_{4}\right)-\right.$ $\left.\left(\mathrm{PhNH}_{2}\right)\right](4)$, cis- $\left[\mathrm{PtBr}_{2}\left(\mathrm{C}_{2} \mathrm{H}_{4}\right)\left(\mathrm{PhNH}_{2}\right)\right](5)$, and cis- $\left[\mathrm{PtBr}_{2}\left(\mathrm{PhNH}_{2}\right)_{2}\right](\mathbf{6})$ have been obtained by efficient one-pot procedures. All have been fully characterized by microanalysis $(\mathrm{C}, \mathrm{H}, \mathrm{N})$, multinuclear NMR spectrometry $\left({ }^{1} \mathrm{H},{ }^{13} \mathrm{C},{ }^{195} \mathrm{Pt}\right)$, UV-visible spectroscopy, and single crystal Xray diffraction. Compound 1 slowly loses $\mathrm{Br}^{-}$in solution to yield $\left(n \mathrm{Bu}_{4} \mathrm{P}\right)_{2}\left[\mathrm{Pt}_{2} \mathrm{Br}_{6}\right]\left(\mathbf{1}^{\prime}\right)$, which has also been characterized crystallographically. The relative stability of the various compounds has been probed experimentally by NMR studies in several solvents and computationally by gas phase geometry optimizations followed by C-PCM calculations of the solvation effects in dichloromethane and aniline. The calculations also included the bis(ethylene) complexes $\left[\mathrm{PtBr}_{2}\left(\mathrm{C}_{2} \mathrm{H}_{4}\right)_{2}\right]$ in the trans (two different conformations 7 and $7^{\prime}$ ) and cis (8) configurations. The solution experiments gave no evidence for a nucleophilic attack of aniline onto coordinated ethylene under mild conditions ( $\mathrm{T}$ up to $68^{\circ} \mathrm{C}$ ), setting a lower limit of $29 \mathrm{kcal} \mathrm{mol}^{-1}$ for the activation barrier of this process. Therefore, the relative energies computed for the other compounds suggest that all ethylene-containing complexes $(\mathbf{2}, \mathbf{4}, \mathbf{5}, \mathbf{7}$ and $\mathbf{8})$ are viable candidates for the key nucleophilic addition step of the $\mathrm{PtBr}_{2}$-catalyzed ethylene hydroamination by aniline. Use of the isolated complexes $\mathbf{2}, \mathbf{4}$ or $\mathbf{5}$ in combination with $n \mathrm{Bu} 4 \mathrm{Br}$ as precatalysts for the ethylene hydroamination by aniline yields similar catalytic activities.

\section{Keywords: platinum, ethylene complexes, aniline complexes, hydroamination, DFT} calculations 


\section{Introduction}

The catalytic hydroamination of non-activated olefins using the combination of air-stable $\mathrm{Pt}^{\mathrm{II}}$ or $\mathrm{Pt}^{\mathrm{IV}}$ halo-salts and phosphonium halides, $n \mathrm{Bu} 4 \mathrm{PX}$ has recently been described. ${ }^{1-4}$ These are amongst the most performing systems ever reported for the hydroamination of ethylene by weakly basic amines such as aniline and 2-chloroaniline (TON > 150 after $10 \mathrm{~h}$ at $150^{\circ} \mathrm{C}, 0.1$ mol \% of $\mathrm{PtBr}_{2}$ and 150 equiv of $n \mathrm{Bu}_{4} \mathrm{PBr}$ for the aniline addition to ethylene). ${ }^{3}$ In addition, they allow the hydroamination of higher olefins such as hexene-1 with a high regioselectivity (95\% Markovnikov). ${ }^{4}$ The catalytic cycle that has been proposed for this system (see Scheme 1$)^{3}$ involves $\left[\mathrm{PtBr}_{4}\right]^{2-}$, which is then transformed into $\left[\mathrm{PtBr}_{3}\left(\mathrm{C}_{2} \mathrm{H}_{4}\right)\right]^{-}$by a substitution reaction with ethylene. Subsequent reaction with aniline gives $\left[\mathrm{PtBr}_{2}\left(\mathrm{ArNH}_{2}\right)\left(\mathrm{C}_{2} \mathrm{H}_{4}\right)\right]\left(\mathrm{Ar}=\mathrm{Ph}\right.$ or $\left.o-\mathrm{C}_{6} \mathrm{H}_{4} \mathrm{Cl}\right)$, which is expected to be more active (more electrophilic) towards nucleophilic attack by aniline on the coordinated ethylene. Nucleophilic attack in complex $\left[\mathrm{PtBr}_{2}\left(\mathrm{ArNH}_{2}\right)\left(\mathrm{C}_{2} \mathrm{H}_{4}\right)\right]$ or $\left[\mathrm{PtBr}_{3}\left(\mathrm{C}_{2} \mathrm{H}_{4}\right)\right]^{-}$then leads to $\left[\mathrm{ArNH}_{2}-\mathrm{CH}_{2}-\mathrm{CH}_{2}-\mathrm{PtBr}_{3}\right]^{-}$, which ultimately evolves to the final product either by direct proton migration from $\mathrm{N}$ to $\mathrm{C}$ (possibly assisted by an external proton shuttle such as a second aniline molecule), or via the $\mathrm{Pt}^{\mathrm{IV}}$ hydrido-complex [ArNH- $\mathrm{CH}_{2}-\mathrm{CH}_{2}-$ $\left.\mathrm{PtHBr}_{3}\right]^{-}$, followed by reductive elimination, as was recently suggested by a DFT-study, performed however on different models $\left(\left[\mathrm{PtCl}\left(\mathrm{PH}_{3}\right)_{2}\left(\mathrm{C}_{2} \mathrm{H}_{4}\right)\right]^{+}\right.$and $\left.\mathrm{NH}_{3}\right){ }^{5}$ A related catalytic cycle based on olefin activation, rather than $\mathrm{N}-\mathrm{H}$ bond activation, has also been proposed for the intermolecular hydroamination of unactivated olefins with carboxamides catalyzed by related $\mathrm{Pt}^{\mathrm{II}}$ catalysts. ${ }^{6}$ The spectacular rate enhancement induced by the large $\mathrm{Br}^{-}$concentration ${ }^{2}$ is probably related to the high negative charge on the $\mathrm{Pt}$ atom in intermediate $\left[\mathrm{ArNH}_{2}-\mathrm{CH}_{2}-\mathrm{CH}_{2}-\mathrm{PtBr}_{3}\right]^{-}$, promoting the intramolecular proton transfer.

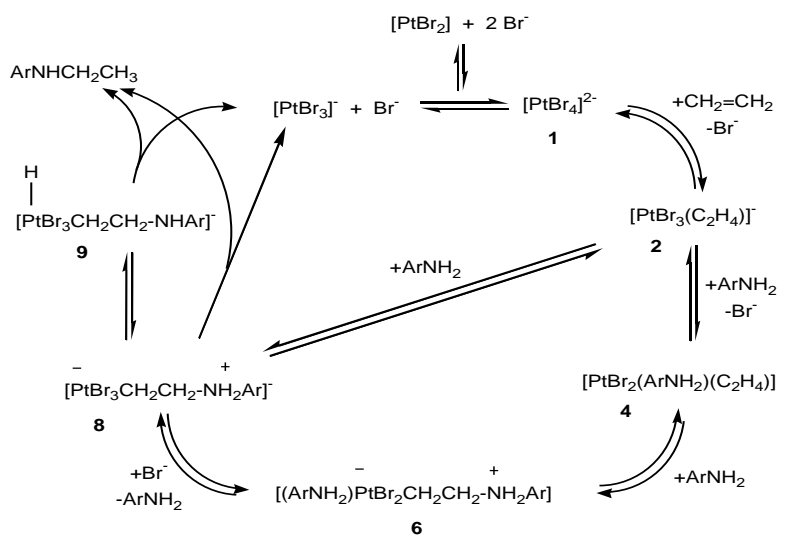

Scheme 1. Proposed " "productive" mechanism for the hydroamination of ethylene by aniline. 
Although this is so far the most efficient system for the intermolecular hydroamination of non-activated olefins, its performance is still largely insufficient for application to industrial scale production. A possible further improvement requires the thorough understanding of the catalytic cycle. Thus, we set out to carry out experimental and computational investigations aimed at elucidating the catalytic cycle and at identifying the nature and energetics of the rate determining step. To this aim, we have isolated and investigated as many of the proposed intermediates as possible, and analysed all the proposed steps. The results obtained from this investigation are organized in two separate contributions. The present article reports the isolation and characterization of all species that participate in the low-energy portion of the catalytic cycle, as well as experimental and computational studies of the equilibria in which these complexes are involved. The second contribution, currently in preparation, will report the computational investigation of the high-energy part of the catalytic cycle.

As will be shown in the present contribution, compound $\left[\mathrm{PtBr}_{2}\left(\mathrm{PhNH}_{2}\right)\left(\mathrm{C}_{2} \mathrm{H}_{4}\right)\right]$ is obtained stereoselectively in the trans geometry by the reaction sequence of Scheme 1. Our synthetic work has also led to the isolation of the new complexes $\left[\mathrm{PtBr}_{3}\left(\mathrm{PhNH}_{2}\right)\right]^{-}$and cis$\left[\mathrm{PtBr}_{2}\left(\mathrm{PhNH}_{2}\right)\left(\mathrm{C}_{2} \mathrm{H}_{4}\right)\right]$, not included in Scheme 1, and to their consideration as intermediates of alternative pathways. For completeness, we have also synthesized and investigated compound cis-[ $\left.\mathrm{PtBr}_{2}\left(\mathrm{PhNH}_{2}\right)_{2}\right]$. Though a few of these complexes have already been reported in the literature, all have been obtained by new and more efficient (one-pot) high-yield syntheses starting from the commercially available Pt-precursors $\mathrm{K}_{2} \mathrm{PtCl}_{4}$ and $\mathrm{K}\left[\mathrm{PtCl}_{3}\left(\mathrm{C}_{2} \mathrm{H}_{4}\right)\right] \cdot \mathrm{H}_{2} \mathrm{O}(\mathrm{Zeise}$ 's salt). Full characterization, namely by multinuclear $\mathrm{NMR}\left({ }^{1} \mathrm{H},{ }^{13} \mathrm{C},{ }^{195} \mathrm{Pt}\right)$ and UV spectroscopies, and by X-ray diffraction is provided for all these complexes. The present study contributes to the understanding of the hydroamination catalytic mechanism by highlighting the presence of previously unsuspected species in the catalytic mixture and to establish the need of their consideration as potential catalytic intermediates.

\section{Results}

\section{(a) Syntheses and characterization}

The synthetic work carried out along this study is summarized in Scheme 2. Potassium tetrachloroplatinate(II) is a less expensive source of platinum than the analogous Br-containing complex and does not suffer from potential contamination, ${ }^{7}$ while it can be quantitatively converted to the all-Br analogue under optimized conditions. Thus, this compound was the choice starting material for our synthetic studies. However, a few synthetic procedures were also carried out from the commercially available Zeise's salt. 


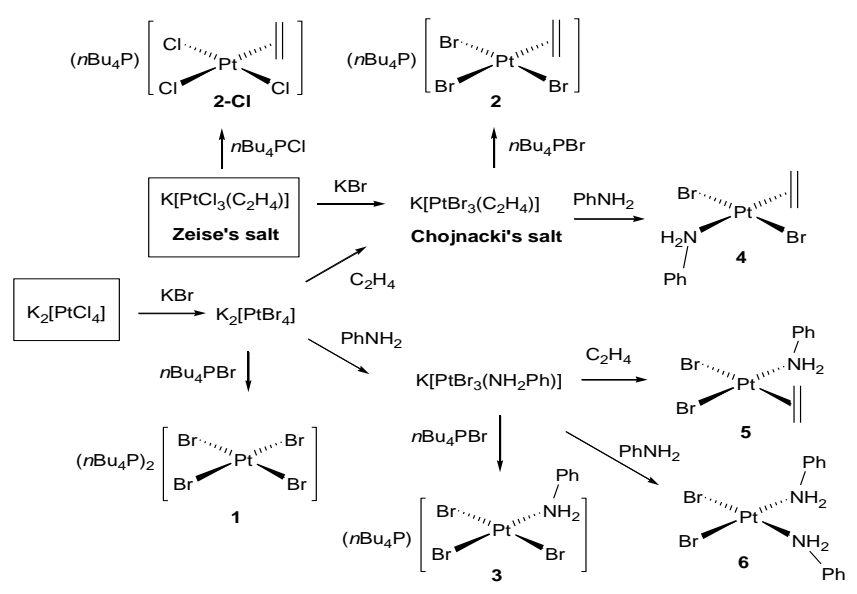

Scheme 2. Synthesis of bromoplatinum(II) complexes in "one-pot" procedures from $\mathrm{K}_{2} \mathrm{PtCl}_{4}$ or Zeise's salt.

Table 1. Physical and microanalytical data

\begin{tabular}{lccccc}
\hline & & & \multicolumn{3}{c}{ anal., \% ${ }^{\mathrm{a}}$} \\
\cline { 4 - 6 } \multicolumn{1}{c}{ cmpd } & color & $\mathrm{mp},{ }^{\circ} \mathrm{C}$ & $\mathrm{C}$ & $\mathrm{H}$ & $\mathrm{N}$ \\
\hline$\left(n \mathrm{Bu}_{4} \mathrm{P}\right)_{2}\left[\mathrm{PtBr}_{4}\right](\mathbf{1})$ & brown-red & $120-121$ & $37.57(37.18)$ & $7.17(7.04)$ & \\
$\left(n \mathrm{Bu}_{4} \mathrm{P}\right)\left[\mathrm{PtBr}_{3}\left(\mathrm{C}_{2} \mathrm{H}_{4}\right)\right](\mathbf{2})$ & yellow & 108 & $29.82(29.93)$ & $5.48(5.59)$ & \\
$\left(n \mathrm{Bu}_{4} \mathrm{P}\right)\left[\mathrm{PtCl}_{3}\left(\mathrm{C}_{2} \mathrm{H}_{4}\right)\right](\mathbf{2}-\mathbf{C l})$ & lemon & 75 & $37.07(36.71)$ & $6.79(6.86)$ & \\
$\left(n \mathrm{Bu}_{4} \mathrm{P}\right)\left[\mathrm{PtBr}_{3}\left(\mathrm{PhNH}_{2}\right)\right](\mathbf{3})$ & red & 124 & $33.62(33.56)$ & $5.64(5.52)$ & $1.55(1.78)$ \\
trans $-\mathrm{PtBr}_{2}\left(\mathrm{PhNH}_{2}\right)\left(\mathrm{C}_{2} \mathrm{H}_{4}\right)(\mathbf{4})$ & yellow & $100(\mathrm{dec})$ & $20.25(20.18)$ & $2.24(2.33)$ & $2.94(2.94)$ \\
cis $-\mathrm{PtBr}_{2}\left(\mathrm{PhNH}_{2}\right)\left(\mathrm{C}_{2} \mathrm{H}_{4}\right)(\mathbf{5})$ & lemon & $120(\mathrm{dec})$ & $19.68(20.18)$ & $1.71(2.33)$ & $2.86(2.94)$ \\
cis $-\mathrm{PtBr}_{2}\left(\mathrm{PhNH}_{2}\right)_{2}(\mathbf{6})$ & greenish & $255(\mathrm{dec})$ & $26.45(26.63)$ & $2.35(2.61)$ & $4.99(5.18)$ \\
\hline
\end{tabular}

${ }^{\mathrm{a}}$ Calculated values in parentheses. 
Table 2. ${ }^{195} \mathrm{Pt},{ }^{1} \mathrm{H}$ and ${ }^{13} \mathrm{C}\left\{{ }^{1} \mathrm{H}\right\}$ NMR data at $25{ }^{\circ} \mathrm{C}$ for the complexes synthesized in this study, together with those of free ethylene for comparison. ${ }^{\mathrm{a}}$

Table 2.

\begin{tabular}{|c|c|c|c|}
\hline Cmpd & ${ }^{195} \mathrm{Pt}$ & ${ }^{1} \mathrm{H}$ & ${ }^{13} \mathrm{C}\left\{{ }^{1} \mathrm{H}\right\}$ \\
\hline $\mathrm{C}_{2} \mathrm{H}_{4}$ & & 5.44 & 122.8 \\
\hline $\mathrm{PhNH}_{2}$ & & $\begin{array}{c}7.17(\mathrm{~m}, 2 \mathrm{H}, m-\mathrm{Ph}), 6.75(\mathrm{~m}, 1 \mathrm{H}, p-\mathrm{Ph}), 6.70(\mathrm{~m}, \\
\left.2 \mathrm{H}, o-\mathrm{NH}_{2}\right) 3.70\left(\mathrm{~s}, 2 \mathrm{H}, \mathrm{NH}_{2}\right)\end{array}$ & $\begin{array}{c}146.8(i-\mathrm{C}), 129.2(m-\mathrm{C}), 118.1(p- \\
\mathrm{C}), 114.8(o-\mathrm{C})\end{array}$ \\
\hline$n \mathrm{Bu}_{4} \mathrm{PBr}^{\mathrm{b}}$ & & $\begin{array}{c}2.72(\mathrm{~m}, 2 \mathrm{H}, \mathrm{PCH}), 1.63\left(\mathrm{~m}, 4 \mathrm{H}, \mathrm{PCH}_{2}\left(\mathrm{CH}_{2}\right)_{2}\right), \\
1.01\left(\mathrm{~m}, 3 \mathrm{H}, \mathrm{P}\left(\mathrm{CH}_{2}\right)_{3} \mathrm{CH}_{3}\right)\end{array}$ & $\begin{array}{c}23.9\left(\mathrm{~d},{ }^{3} J_{\mathrm{C}-\mathrm{P}}=15 \mathrm{~Hz}, \mathrm{C}_{\mathrm{C}}\right), 23.7(\mathrm{~d} \\
\left.{ }^{2} J_{\mathrm{C}-\mathrm{P}}=5 \mathrm{~Hz}, \mathrm{C}_{\mathrm{B}}\right), 19.1\left(\mathrm{~d},{ }^{1} J_{\mathrm{C}-\mathrm{P}}=\right. \\
\left.47.5 \mathrm{~Hz}, \mathrm{C}_{\mathrm{A}}\right), 13.3\left(\mathrm{~s}, \mathrm{C}_{\mathrm{D}}\right)\end{array}$ \\
\hline$\left(n \mathrm{Bu}_{4} \mathrm{P}\right)_{2}\left[\mathrm{PtBr}_{4}\right](\mathbf{1})$ & $-2528\left(\mathrm{bs}, \Delta \delta_{1 / 2}=98\right)$ & & \\
\hline$\left(n \mathrm{Bu}_{4} \mathrm{P}\right)\left[\mathrm{PtBr}_{3}\left(\mathrm{C}_{2} \mathrm{H}_{4}\right)\right](\mathbf{2})$ & $-3429\left(\right.$ quint, $\left.{ }^{2} J_{\mathrm{Pt}-\mathrm{H}}=65\right)$ & $4.59\left(\mathrm{~s}+\mathrm{d} 1: 10: 1,{ }^{2} J_{\mathrm{H}-\mathrm{Pt}}=65\right)$ & $67.3\left(\mathrm{~s}+\mathrm{d},{ }^{1} J_{\mathrm{C}-\mathrm{Pt}}=176.4\right)$ \\
\hline$\left(n \mathrm{Bu}_{4} \mathrm{P}\right)\left[\mathrm{PtCl}_{3}\left(\mathrm{C}_{2} \mathrm{H}_{4}\right)\right](\mathbf{2}-\mathbf{C l})$ & $-2743\left(\right.$ quint, $\left.{ }^{2} J_{\mathrm{Pt}-\mathrm{H}}=65\right)$ & $4.63\left(\mathrm{~s}+\mathrm{d} 1: 10: 1,{ }^{2} J_{\mathrm{H}-\mathrm{Pt}}=65\right)$ & $68.0\left(\mathrm{~s}+\mathrm{d},{ }^{1} J_{\mathrm{C}-\mathrm{Pt}}=191.8\right)$ \\
\hline$\left(n \mathrm{Bu}_{4} \mathrm{P}\right)\left[\mathrm{PtBr}_{3}\left(\mathrm{PhNH}_{2}\right)\right](\mathbf{3})$ & $-2422\left(\mathrm{bs}, \Delta \delta_{1 / 2}=250\right)$ & $\begin{array}{c}5.64\left(\mathrm{~s}+\mathrm{d} 1: 10: 1,2 \mathrm{H},{ }^{2} J_{\mathrm{H}-\mathrm{Pt}}=72, \mathrm{C}_{6} \mathrm{H}_{5} \mathrm{NH}_{2}\right), \\
\left.\text { 7.17-7.59(m, 5H, } \mathrm{C}_{6} H_{5} \mathrm{NH}_{2}\right)\end{array}$ & $\begin{array}{c}122.2(o-\mathrm{C}), 125.5(p-\mathrm{C}), 128.9(\mathrm{~m}- \\
\mathrm{C}), 141.0(\mathrm{i}-\mathrm{C})\end{array}$ \\
\hline $\begin{array}{l}\text { trans }-\mathrm{PtBr}_{2}\left(\mathrm{C}_{2} \mathrm{H}_{4}\right)\left(\mathrm{PhNH}_{2}\right) \\
(\mathbf{4})^{\mathrm{c}}\end{array}$ & $-3525\left(\mathrm{bs}, \Delta \delta_{1 / 2}=240\right)$ & $\begin{array}{c}4.82\left(\mathrm{~s}+\mathrm{d} 1: 10: 1,4 \mathrm{H},{ }^{2} J_{\mathrm{H}-\mathrm{Pt}}=65, \mathrm{C}_{2} H_{4}\right) \\
6.23\left(\mathrm{br}, \Delta \delta_{1 / 2}=26,2 \mathrm{H}, \mathrm{C}_{6} \mathrm{H}_{5} \mathrm{NH}_{2}\right) \\
\left.\text { 7.3-7.6 (m, 5H, } \mathrm{C}_{6} H_{5} \mathrm{NH}_{2}\right)\end{array}$ & $\begin{array}{l}71.5\left(\mathrm{~s}+\mathrm{d},{ }^{1} J_{\mathrm{C}-\mathrm{Pt}}=164.4\right), \\
122.3(o-\mathrm{C}), 126.8(p-\mathrm{C}), \\
129.6(\mathrm{~m}-\mathrm{C}), 137.8(i-\mathrm{C})\end{array}$ \\
\hline cis- $\mathrm{PtBr}_{2}\left(\mathrm{C}_{2} \mathrm{H}_{4}\right)\left(\mathrm{PhNH}_{2}\right)(\mathbf{5})^{\mathrm{d}}$ & $-3066\left(\mathrm{bs}, \Delta \delta_{1 / 2}=400\right)$ & $\begin{array}{c}4.49\left(\mathrm{~s}+\mathrm{d} 1: 10: 1,4 \mathrm{H},{ }^{2} J_{\mathrm{H}-\mathrm{Pt}}=63.9, \mathrm{C}_{2} H_{4}\right) \\
7.65\left(\mathrm{br}, \Delta \delta_{1 / 2}=26,2 \mathrm{H}, \mathrm{C}_{6} \mathrm{H}_{5} \mathrm{NH}_{2},{ }^{2} J_{\mathrm{H}-\mathrm{Pt}}=64 \mathrm{~Hz}\right) \\
7.25-7.59\left(\mathrm{~m}, 5 \mathrm{H}, \mathrm{C}_{6} H_{5} \mathrm{NH}_{2}\right)\end{array}$ & $\begin{array}{l}70.3\left(\mathrm{~s}+\mathrm{d},{ }^{1} J_{\mathrm{C}-\mathrm{Pt}}=184.0\right) \\
123.4(o-\mathrm{C}), 126.6(p-\mathrm{C}), 129.5(m- \\
\mathrm{C}), 140.5(i-\mathrm{C})\end{array}$ \\
\hline cis- $\mathrm{PtBr}_{2}\left(\mathrm{PhNH}_{2}\right)_{2}(\mathbf{6})^{\mathrm{d}}$ & $-2397\left(\mathrm{br}, \Delta \delta_{1 / 2}=400\right)$ & $\begin{array}{c}7.54\left(\mathrm{br}, 4 \mathrm{H}, \mathrm{C}_{6} \mathrm{H}_{5} \mathrm{NH}_{2}\right) \\
\left.\text { 7.3-7.6 (m, } 10 \mathrm{H}, \mathrm{C}_{6} \mathrm{H}_{5} \mathrm{NH}_{2}\right)\end{array}$ & $\begin{array}{c}123.5(o-\mathrm{C}), 125.6(p-\mathrm{C}), 128.8(\mathrm{~m}- \\
\mathrm{C}), 142.4(i-\mathrm{C})\end{array}$ \\
\hline
\end{tabular}


$\left(n \mathbf{B u}_{4} \mathbf{P}\right)_{2}\left[\mathbf{P t B r}_{4}\right](1)$ and $\left(n \mathbf{B u}_{4} \mathbf{P}\right)_{2}\left[\mathbf{P t}_{2} \mathbf{B r}_{6}\right]\left(\mathbf{1}^{\prime}\right)$. There are two main access routes to $\left[\mathrm{PtBr}_{4}\right]^{2-}$ in the literature: (a) reduction of $\mathrm{K}_{2} \mathrm{PtBr}_{6}$ by $\mathrm{N}_{2} \mathrm{H}_{6} \mathrm{SO}_{4}$ or $\mathrm{K}_{2} \mathrm{C}_{2} \mathrm{O}_{4}{ }^{8}$ and b) halide exchange from $\mathrm{K}_{2} \mathrm{PtCl}_{4}$ and $\mathrm{KBr}$ on a steam bath, ${ }^{9},{ }^{10}$ though a detailed description of the experimental procedure is not available. Furthermore, the similar solubility of all salts renders the separation difficult, leading to low yields of the pure final product. From the recent literature, ${ }^{11}$ compound $\left(\mathrm{Bu}_{4} \mathrm{~N}\right)_{2}\left[\mathrm{PtBr}_{4}\right]$ was obtained in $80 \%$ yield from $\mathrm{K}_{2} \mathrm{PtCl}_{4}$ and $\mathrm{KBr}$ (saturated water solution), followed by extraction by $\mathrm{Bu}_{4} \mathrm{NBr} / \mathrm{CH}_{2} \mathrm{Cl}_{2}$. However, very large $\mathrm{KBr}$ quantities are necessary to yield a saturated aqueous solution and this excess makes the purification more problematic. We have sought to solve this problem by keeping the amount of $\mathrm{KBr}$ to the minimum amount required to insure a quantitative exchange (as monitored by ${ }^{195} \mathrm{Pt}$ NMR, see Experimental section) and subsequently extracting the Pt complex into an organic solvent by cation exchange. Thus, use of a $\mathrm{CH}_{2} \mathrm{Cl}_{2}$ solution of $n \mathrm{Bu} 4 \mathrm{PBr}$ gave $\left(n \mathrm{Bu}_{4} \mathrm{P}\right)_{2}\left[\mathrm{PtBr}_{4}\right](\mathbf{1})$ in $68 \%$ yield from $\mathrm{K}_{2} \mathrm{PtCl}_{4}$ and 90 equiv $\mathrm{KBr}$ in water under mild conditions, see experimental section (Scheme 3). The structure of $\mathbf{1}$ was determined by a single crystal X-Ray diffraction study. The anion has the expected square planar configuration. A view of the dianion and the selected bond distances and angles are provided in the supporting information. The average PtBr distance in the dianion $(2.424 \AA)$ compares well with the value of $2.419 \AA$ reported for the same ion in $[\mathrm{PtBr}(\text { dien })]_{2}\left[\mathrm{PtBr}_{4}\right]$ (dien $\left.=\mathrm{NH}_{2} \mathrm{CH}_{2} \mathrm{CH}_{2} \mathrm{NHCH}_{2} \mathrm{CH}_{2} \mathrm{NH}_{2}\right) .{ }^{12}$ Significantly longer distances, however, were found for the anhydrous $(2.445(2) \AA)^{13}$ and hydrated ${ }^{14}(2.446(6)$, 2.43(1) $\AA$ ) $\mathrm{K}_{2} \mathrm{PtBr}_{4}$ salt, possibly resulting from the Coulombic effect of the $\mathrm{K}^{+} \ldots \mathrm{Br}^{\delta^{-}}$ interactions.

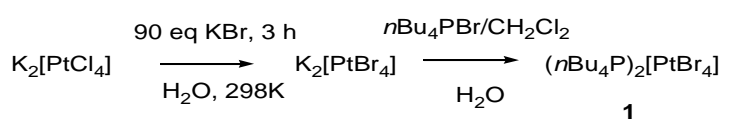

\section{Scheme 3.}

Compound 1 very slowly transforms into $\left[n \mathrm{Bu}_{4} \mathrm{P}\right]_{2}\left[\mathrm{Pt}_{2} \mathrm{Br}_{6}\right]\left(\mathbf{1}^{\prime}\right)$ in $\mathrm{CD}_{2} \mathrm{Cl}_{2}$ solution $(\sim 10 \%$, 5 days; ${ }^{195} \mathrm{Pt}$ resonance at $\left.-2306 \mathrm{ppm}\right)$. The same observation has been previously reported for the $n \mathrm{Bu}_{4} \mathrm{~N}^{+}$salt. ${ }^{11}$ The structure of $\left[n \mathrm{Bu}_{4} \mathrm{P}_{2}\left[\mathrm{Pt}_{2} \mathrm{Br}_{6}\right]\right.$ has also been determined by $\mathrm{X}$-ray diffraction (see geometry and selected bonding parameters of the dianion in the SI, Figure S2 and Table S2). The geometry is in good agreement with that determined previously for the corresponding $\mathrm{NEt}_{4}{ }^{+}$salt. $^{15,16}$

$\left(n \mathbf{B u}_{4} \mathbf{P}\right)\left[\operatorname{PtBr}_{3}\left(\mathbf{C}_{2} \mathrm{H}_{4}\right)\right]$ (2). Compound $\mathrm{K}\left[\mathrm{PtBr}_{3}\left(\mathrm{C}_{2} \mathrm{H}_{4}\right)\right] \cdot \mathrm{H}_{2} \mathrm{O}$, first reported in $1870^{17}$ and known ${ }^{18}$ as Chojnacki's salt, is generally prepared in the same manner as Zeise's salt, namely by 
bubbling $\mathrm{C}_{2} \mathrm{H}_{4}$ through a $\mathrm{K}_{2}\left[\mathrm{PtBr}_{4}\right]$ solution. ${ }^{19}$ It has also been obtained by halide exchange from Zeise's salt, ${ }^{20}$ but long reaction times and a protecting ethylene atmosphere were necessary to avoid the formation of $\left[\mathrm{PtBr}_{4}\right]^{2-}$ and no elemental analysis, yields and physical data were reported. A compound of stoichiometry $\left(\mathrm{Bu}_{4} \mathrm{~N}\right)\left[\mathrm{PtBr}_{3}\left(\mathrm{C}_{2} \mathrm{H}_{4}\right)\right]$, characterized by IR spectroscopy, was mentioned ${ }^{21}$ but no detailed synthetic procedure has appeared in the literature to the best of our knowledge. We describe here a direct synthesis of 2 in $46 \%$ yield from $\mathrm{K}_{2} \mathrm{PtCl}_{4}$, as well as by an alternative procedure from Zeise's salt (61\% yield of isolated pure product), see Scheme 4. The ethanol used as a solvent for the transformation of $\mathrm{K}_{2}\left[\mathrm{PtBr}_{4}\right]$ into $\mathrm{K}\left[\mathrm{PtBr}_{3}\left(\mathrm{C}_{2} \mathrm{H}_{4}\right)\right]$ serves to remove the large $\mathrm{KBr}$ excess from the previous step and also appears to speed up the ligand exchange relative to water, while the presence of small amounts of $\mathrm{HBr}$ avoids decomposition to unknown compounds. The other procedure from Zeise's salt uses the same strategy described above for $\mathbf{1}$, namely halide exchange with the minimum amount of $\mathrm{KBr}$, followed by cation exchange and operating under an ethylene atmosphere. Compound $\left(n \mathrm{Bu}_{4} \mathrm{P}\right)\left[\mathrm{PtCl}_{3}\left(\mathrm{C}_{2} \mathrm{H}_{4}\right)\right](\mathbf{2}-\mathbf{C l})$ has similarly been obtained by cation exchange from Zeise's salt.

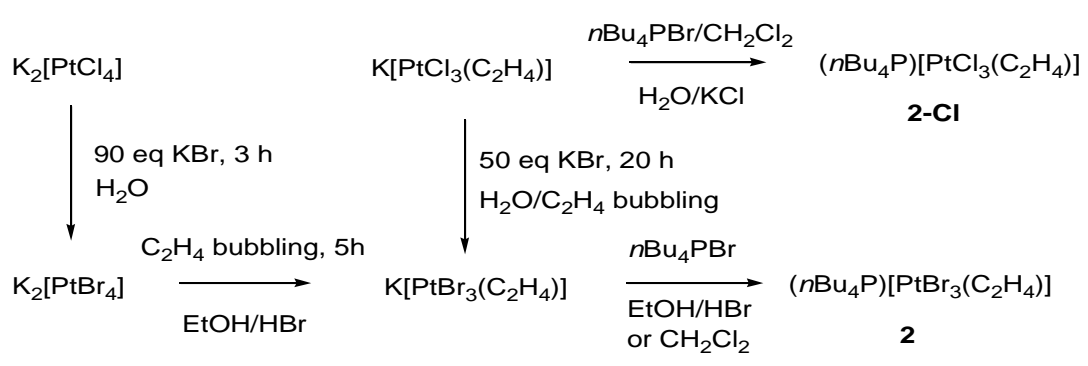

\section{Scheme 4.}

The ${ }^{1} \mathrm{H}$ NMR spectrum of 2 in $\mathrm{CD}_{2} \mathrm{Cl}_{2}$ features a single resonance with ${ }^{195} \mathrm{Pt}$ satellites at $\delta$ $4.59 \mathrm{ppm}\left({ }^{2} J_{\mathrm{H}-\mathrm{Pt}}=65\right)$ due to the olefinic protons, upfield from those of free ethylene $(\delta 5.44)$ and 2-CI ( $\delta$ 4.63). This indicates a greater degree of $\mathrm{Pt}_{-} \mathrm{C}_{2} \mathrm{H}_{4} \pi$ back-bonding for the bromide system. Likewise, the ${ }^{13} \mathrm{C}\left\{{ }^{1} \mathrm{H}\right\}$ singlet resonance of 2 at $\delta 67.3\left({ }^{1} J_{\mathrm{C}-\mathrm{Pt}}=176.4 \mathrm{~Hz}\right)$ is upfield from those of 2-Cl $\left(\delta 68.0,{ }^{1} J_{\mathrm{C}-\mathrm{Pt}}=191.8 \mathrm{~Hz}\right)$ and free $\mathrm{C}_{2} \mathrm{H}_{4}(\delta 122.8)$. Note, however, that ${ }^{1} J_{\mathrm{C}-\mathrm{Pt}}$ is higher for Zeise's anion. A greater degree of $\mathrm{Pt}_{-} \mathrm{C}_{2} \mathrm{H}_{4} \pi$ back-bonding for 2 relative to the corresponding trichloro anion is also suggested by the IR stretching frequency of two bands in which contribution of the $\mathrm{C}=\mathrm{C}$ bond stretch is important [because of vibrational coupling with $\left.\delta_{\mathrm{S}}\left(\mathrm{CH}_{2}\right)\right]^{22-25}$ (1510 and $1227 \mathrm{~cm}^{-1}$, vs. 1516 and $1230 \mathrm{~cm}^{-1}$ for compound 2-Cl and 1623 and $1342 \mathrm{~cm}^{-1}$ for free ethylene ${ }^{26}$ ).

The structure of the $\left[\mathrm{PtBr}_{3}\left(\mathrm{C}_{2} \mathrm{H}_{4}\right)\right]^{-}$ion was previously studied ${ }^{27}$ only for the potassium salt by two-dimensional methods and showed a significantly longer Pt-Br bond trans to the ethylene 
ligand $(2.52 \AA)$ than for the two Pt-Br bonds cis to ethylene ligand ( 2.43 and $2.42 \AA$, the estimated standard deviation being $0.01 \AA$ ), interpreted as the result of the stronger olefin trans influence. The $\mathrm{C}$ atom positions were not precisely determined and for this reason the $\mathrm{C}=\mathrm{C}$ and Pt-C distances were not reported. In the course of our work we have obtained single crystals of $\left(n \mathrm{Bu}_{4} \mathrm{P}\right)\left[\mathrm{PtBr}_{3}\left(\mathrm{C}_{2} \mathrm{H}_{4}\right)\right]$. A view of the anion geometry with selected bond distances and angles is presented in Figure 1. A more extended list and comparison with DFT calculated parameters is presented in the SI (Table S3).

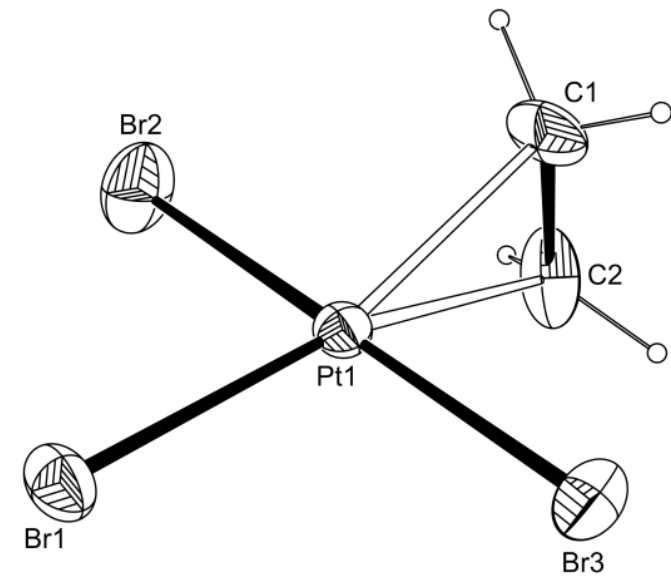

Figure 1. Molecular structure of anion of $\mathbf{2}$ with ellipsoids are drawn at the $30 \%$ probability level. Selected bond distances (̊̊): Pt-Br1, 2.4294(14); Pr-Br2, 2.4229(16); Pt-Br3, 2.4337(14); C1-C2, 1.37(2).

In this structure, there is no significant difference between the lengths of the three $\mathrm{Pt}-\mathrm{Br}$ bonds. Differences in crystal packing $\left(n \mathrm{Bu}_{4} \mathrm{P}^{+} v s . \mathrm{K}^{+}\right.$and the presence of one $\mathrm{H}_{2} \mathrm{O}$ molecule in the latter salt) could be responsible for this effect. Note that a greater discrepancy between trans and cis lengths was also observed in two-dimensional determinations of Zeise's salt ${ }^{27-30}$ (e.g. 2.39 for $\mathrm{Cl}_{\text {trans }}$ vs.2.29 and $2.27 \AA$ for $\mathrm{Cl}_{\text {cis }}$ ), relative to the more precise 3-dimensional X-ray study [2.327(5) vs. 2.314(7) and 2.296(7) $\AA)^{31}$ and to a neutron diffraction study (2.340(2) vs. 2.302(2) and 2.303(2) $\AA$ ] ${ }^{32}$ The $\mathrm{C}=\mathrm{C}$ distance is identical to that measured in Zeise's salt [1.37(3) A by X-ray and 1.375(4) A by neutron diffraction].

$(\boldsymbol{n B u} 4 \mathbf{P})\left[\operatorname{PtBr}_{3}\left(\mathbf{P h N H}_{2}\right)\right]$ (3). This compound, containing the previously unreported $\left[\mathrm{PtBr}_{3}\left(\mathrm{PhNH}_{2}\right)\right]^{-}$ion, was obtained in the same manner as $2\left(41 \%\right.$ yield from $\left.\mathrm{K}_{2} \mathrm{PtCl}_{4}\right)$, when aniline was used instead of $\mathrm{C}_{2} \mathrm{H}_{4}$ (Scheme 5). However, the reaction must be carried out under acidic conditions $(\mathrm{pH}=2)$. When neutral conditions were used a precipitate with a stoichiometry close to $\mathrm{PtBr}_{2}\left(\mathrm{PhNH}_{2}\right)_{2}$, according to the analytical data, immediately formed upon addition of 1 equiv of aniline. The ${ }^{1} \mathrm{H}$ NMR spectrum of 3 in $\mathrm{CD}_{2} \mathrm{Cl}_{2}$ features a single and slightly broadened $\left(\Delta \delta_{1 / 2}=15 \mathrm{~Hz}\right)$ resonance with ${ }^{195} \mathrm{Pt}$ satellites at $\delta 5.64 \mathrm{ppm}\left({ }^{2} J_{\mathrm{H}-\mathrm{Pt}}=72 \mathrm{~Hz}\right)$ for the $\mathrm{NH}_{2}$-protons (cf. 3.69 for free aniline). 
$\left.\mathrm{K}_{2}\left[\mathrm{PtCl}_{4}\right] \underset{\mathrm{H}_{2} \mathrm{O}, \mathrm{pH}=2}{90 \text { eq KBr, } 3 \mathrm{~h}} \mathrm{~K}_{2}\left[\mathrm{PtBr}_{4}\right] \underset{\mathrm{H}_{2} \mathrm{O}, \mathrm{pH}=2}{\stackrel{1}{\longrightarrow}} \mathrm{K}^{\longrightarrow} \mathrm{PtBr}_{3}(\mathrm{an})\right] \underset{\mathrm{H}_{2} \mathrm{O}, \mathrm{pH}=2}{\stackrel{n \mathrm{Bu}_{4} \mathrm{PBr}_{2} \mathrm{CH}_{2} \mathrm{Cl}_{2}}{\longrightarrow}}\left(n \mathrm{Bu}_{4} \mathrm{P}\right)\left[\mathrm{PtBr}_{3}(\mathrm{an})\right]$

\section{Scheme 5.}

The structure of the $\left[\mathrm{PtBr}_{3}\left(\mathrm{PhNH}_{2}\right)\right]^{-}$ion in compound 3 shows the expected square planar geometry, see Figure 2. Selected bond distances and angles are presented in the SI (Table S4). To date, the Cambridge Structural Database (CSD) contains 48 structures of type $\left[\mathrm{PtX}_{3} \mathrm{~L}\right]^{-}$, with $\mathrm{X}=$ halogen and $\mathrm{L}=\mathrm{N}$-based donor, most of which feature chlorides and aromatic $\mathrm{N}$ heterocycles as donors. In none of these structures is the $\mathrm{N}$-donor ligand aniline or another aryl amine. Indeed aryl amines are much less basic than either aliphatic amines or heterocyclic $\mathrm{N}$ donor ligands (e.g. pyridine) and the structural chemistry of platinum complexes with these ligands is essentially unexplored. The only precedents of structurally characterized aniline derivatives appear to be trans $-\mathrm{PtI}_{2}\left(\mathrm{NH}_{2}-\mathrm{C}_{6} \mathrm{H}_{4}-4-\mathrm{R}\right)_{2}(\mathrm{R}=\mathrm{Et}, i \mathrm{Pr})$, where the Pt-N distance is 2.060(7) and 2.029(11) $\AA$, respectively. ${ }^{33}$ Similarly to the above-discussed complex 2 , the $\mathrm{Pt}-\mathrm{Br}$ distances in compound $\mathbf{3}$ do not differ significantly between cis and trans positions. The average Pt-Br bond length in 3, 2.443(5) $\AA$, is significantly longer than the same average in 2, 2.429(5) $\AA$, but also longer than those found for other $\left[\mathrm{PtBr}_{3}(\mathrm{~L})\right]^{-}$complexes containing $\mathrm{N}$-donor ligands (in the 2.416-2.431 ̊ range). ${ }^{34-39}$

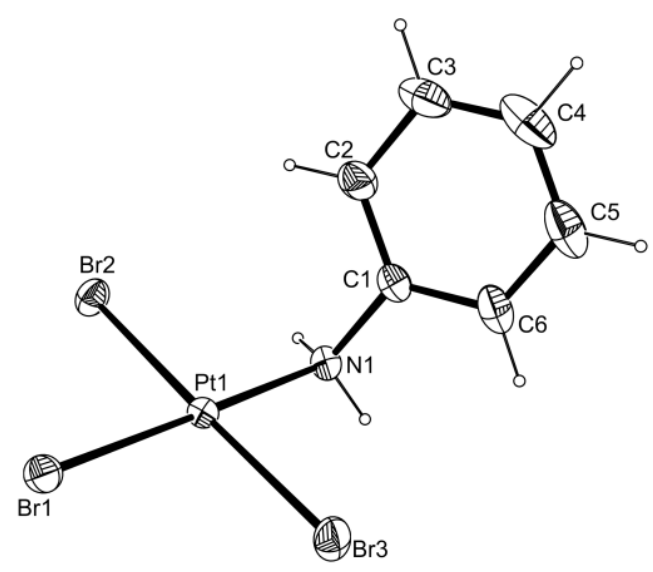

Figure 2. Molecular structure of the anion of $\mathbf{3}$ with molecular ellipsoids are drawn at the $30 \%$ probability level. Selected distances $(\AA)$ : Pt-Br1, 2.4444(9); Pt-Br2, 2.4487(7); PtBr3, 2.4375(7), Pt-N1, 2.078(4).

trans-[PtBr2 $\left.\left(\mathbf{P h N H}_{2}\right)\left(\mathbf{C}_{2} \mathbf{H}_{4}\right)\right]$ (4). This compound has already been reported, its synthesis starting from Chojnacki's salt. ${ }^{40,41} \mathrm{We}$ have now optimized a one-pot synthetic procedure from 
$\mathrm{K}_{2} \mathrm{PtCl}_{4}$ in $49 \%$ yield. Alternatively, starting from Zeise's salt (halide exchange first, then aniline addition), a yield of $73 \%$ was obtained (Scheme 6). It should be noted that $\mathbf{4}$, as well as all $n \mathrm{Bu}_{4} \mathrm{P}$ salts described in this paper, is not soluble in water. This provides a driving force for the ligand exchange reaction, because the anionic tribromo anion is in fact thermodynamically preferred in solution (see equilibrium studies below). The exclusive formation of the trans isomer can be explained by the well known trans-effect of the $\mathrm{C}_{2} \mathrm{H}_{4}$ ligand.

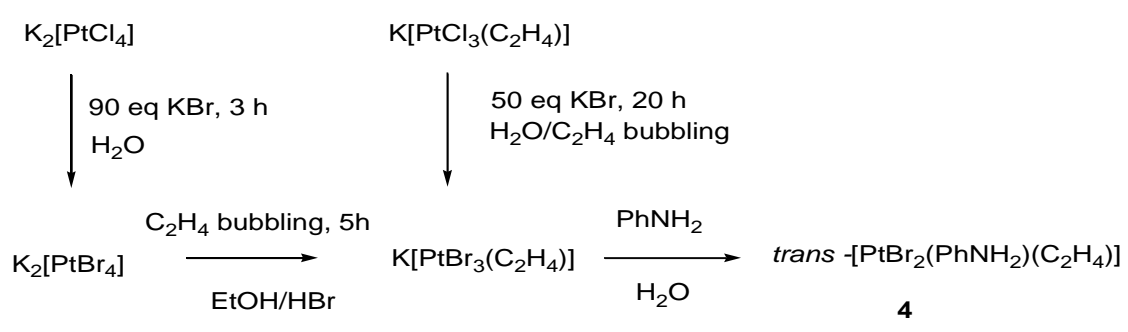

\section{Scheme 6.}

Compound 4 exhibits a single ${ }^{13} \mathrm{C}\left\{{ }^{1} \mathrm{H}\right\}$ NMR resonance with ${ }^{195} \mathrm{Pt}$ satellites at $\delta 71.5 \mathrm{ppm}$ $\left({ }^{1} J_{\mathrm{C}-\mathrm{Pt}}=164.4 \mathrm{~Hz}\right)$, downfield from Zeise's anion $(\delta 68.0)$ and Chajnacki's anion $(\delta 67.3 \mathrm{ppm})$, in agreement with a decrease of $\pi$ back-bonding in the order $\left[\mathrm{PtBr}_{3}\left(\mathrm{C}_{2} \mathrm{H}_{4}\right)\right]^{-}>\left[\mathrm{PtCl}_{3}\left(\mathrm{C}_{2} \mathrm{H}_{4}\right)\right]^{-}>$ trans- $\left[\mathrm{PtBr}_{2}\left(\mathrm{PhNH}_{2}\right)\left(\mathrm{C}_{2} \mathrm{H}_{4}\right)\right]$. This correlates with the blue shift observed for the $v_{\mathrm{C}=\mathrm{C}}$ vibration in the IR spectrum along the same series (first band: $1510<1515<1519$; second band: $1227<$ $1230<1252$; all values in $\left.\mathrm{cm}^{-1}\right)$. The ${ }^{1} \mathrm{H}$ NMR spectrum exhibits a singlet at $\delta 4.82 \mathrm{ppm}\left({ }^{2} J_{\mathrm{H}-\mathrm{Pt}}=\right.$ $65 \mathrm{~Hz}$ ) for the ethylene ligand, upfield from free ethylene (5.44 ppm) but downfield from Zeise's anion (4.63 ppm) and Chojnacki's anion (4.59 ppm). The aniline ligand shows a broad resonance at $\delta 6.23\left(\Delta \delta_{1 / 2}=26 \mathrm{~Hz}\right)$, attributed to the $\mathrm{NH}_{2}$-protons. The broadness and absence of observable ${ }^{195} \mathrm{Pt}$ coupling for this resonance, compared with the narrower and ${ }^{195} \mathrm{Pt}$-coupled resonance for $\mathbf{3}$, is suggestive of molecular dynamics, which includes the possible exchange with minor traces of residual free aniline, as already reported for other related systems. ${ }^{42,43}$ This point will be addressed in greater detail below. The UV-visible spectrum of $\mathbf{4}$ in dichloromethane shows a strong UV absorption at $263 \mathrm{~nm}\left(\varepsilon=4950 \mathrm{~cm}^{-1} \mathrm{M}^{-1}\right)$ which compares with the reported $^{40}$ value of $264 \mathrm{~nm}\left(\varepsilon=4158 \mathrm{~cm}^{-1} \mathrm{M}^{-1}\right)$ in $\mathrm{MeOH}$, and two previously unreported shoulders at $\lambda_{\max }$ ca. $310 \mathrm{~nm}\left(\varepsilon=1280 \mathrm{~cm}^{-1} \mathrm{M}^{-1}\right)$ and ca. $340 \mathrm{~nm}\left(\varepsilon=605 \mathrm{~cm}^{-1} \mathrm{M}^{-1}\right)$, the tailing of which in the visible range is responsible for the observed yellow color.

The single crystal X-ray analysis of $\mathbf{4}$ shows two independent and essentially identical molecules in the asymmetric unit, one of which is shown in Figure 3 with selected bonding parameters. The crystal packing reveals a 3-dimensional network of $\mathrm{NH}_{2} \cdots \mathrm{Br} \mathrm{H}$-bonding (see Figure S3). Additional bonding parameters are available in the SI (Table S5). As stated above, the coordination chemistry of $\mathrm{Pt}^{\mathrm{II}}$ with aryl amines has been little explored. The Pt-N distance in 
compound 4 is longer than those mentioned in the previous section for $\left[\mathrm{PtX}_{3} \mathrm{~L}\right]^{-}$complexes, presumably because of the strong trans influence of the ethylene ligand. Other trans$\left[\mathrm{PtX}_{2}\right.$ (alkene)(L)] complexes (all containing alkylamine or $\mathrm{N}$-based heterocyclic ligands and $\mathrm{X}=$ $\mathrm{Cl})$ also have longer Pt-N distances, for instance 2.084(11) $\AA$ for trans- $\mathrm{PtCl}_{2}\left(\mathrm{C}_{2} \mathrm{H}_{4}\right)(2,6$ $\left.\mathrm{NC}_{5} \mathrm{H}_{3} \mathrm{Me}_{2}\right)^{44}$ and 2.09(5) for trans $-\mathrm{PtCl}_{2}\left[\mathrm{CH}_{2}=\mathrm{CHCH}(\mathrm{Me}) \mathrm{Et}\right]\left(\mathrm{NH}_{2} \mathrm{CH}_{2} \mathrm{Ph}\right) .{ }^{45}$ The C-C distance compares with the distance found in $\mathrm{C}_{2} \mathrm{H}_{4}$ coordinated to square planar $\mathrm{Pt}^{\mathrm{II}}$ (average of 1.38(2) $\AA$ for 28 structures retrieved from the CSD).

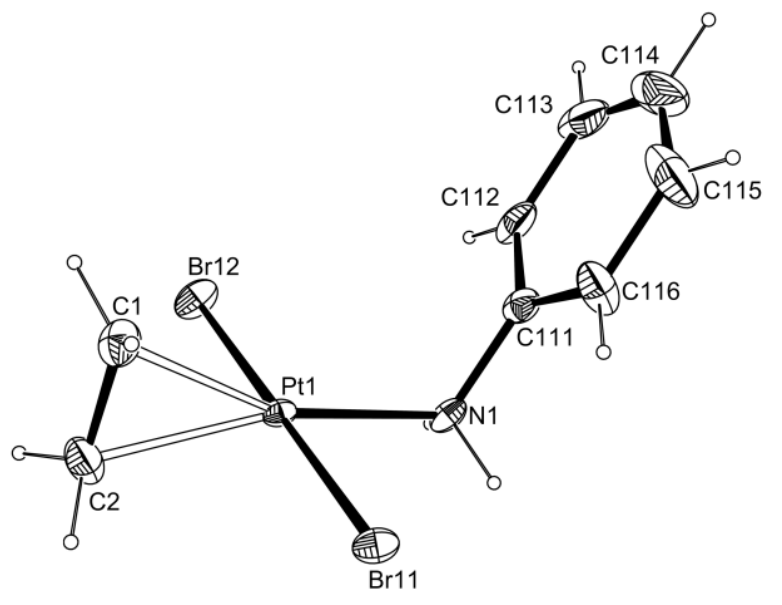

Figure 3. An ORTEP view of one of the two independent molecules of 4. Molecular ellipsoids are drawn at the $30 \%$ probability level. Selected bond distances $(\AA$; values separated by slashes are the corresponding parameters in two crystallographically independent molecules): Pt1-Br11, 2.4108(6)/2.4093(7); Pt1-Br12, 2.4203(6)/2.4237(7); Pt1-N1, 2.093(4)/2.093(5); Pt1-C1, 2.155(6)/2.158(7); Pt1-C2, 2.145(6)/2.153(6); C1-C2, $1.378(10) / 1.375(9)$.

cis-[PtBr $\left.2\left(\mathbf{P h N H}_{2}\right)\left(\mathbf{C}_{2} \mathbf{H}_{4}\right)\right]$ (5). Compound cis-[ $\left.\mathrm{PtBr}_{2}\left(\mathrm{PhNH}_{2}\right)\left(\mathrm{C}_{2} \mathrm{H}_{4}\right)\right]$ was obtained in a one-pot procedure in $42 \%$ isolated yield from $\mathrm{K}_{2} \mathrm{PtCl}_{4}$ (Scheme 7), by exchanging the order of addition of the neutral ligands relative to the synthesis of the trans isomer described above. The reaction is stereoselective because of the trans-effect pattern $\left(\mathrm{Br}^{-}>\mathrm{PhNH}_{2}\right)$. Compound $\mathbf{5}$ is not soluble in $\mathrm{H}_{2} \mathrm{O}$ and in low-polarity organic solvents $\left(\mathrm{CH}_{2} \mathrm{Cl}_{2}, \mathrm{THF}\right)$, sparingly soluble in acetone and soluble in DMF; it is not stable in DMSO. ${ }^{46}$ The ${ }^{1} \mathrm{H}$ NMR spectrum in DMF- $d_{7}$ features a broad resonance $\left(\Delta \delta_{1 / 2}=26 \mathrm{~Hz}\right)$ with ${ }^{195} \mathrm{Pt}$ satellites for the $\mathrm{NH}_{2}$ protons at $\delta 7.62\left({ }^{2} J_{\mathrm{H}-\mathrm{Pt}}=64\right.$ $\mathrm{Hz}$ ), namely considerably upfield with respect to the corresponding resonance of the trans isomer 4 ( $\delta 8.26$ in the same solvent). Note also that the Pt satellites are visible for this compound and for compound $\mathbf{3}$, but not for the trans isomer $\mathbf{4}$. Both observations may be related 
to the stronger aniline ligand binding in the cis isomer (vide infra). The $\mathrm{C}=\mathrm{C}$ vibrations (1513 and $1236 \mathrm{~cm}^{-1}$ ) are red-shifted relative to those of the trans analogue $\left(1519\right.$ and $\left.1252 \mathrm{~cm}^{-1}\right)$. These data concur to suggest a greater extent of $\mathrm{Pt}-\mathrm{C}_{2} \mathrm{H}_{4}$ back-bonding for the cis isomer. The ethylene protons give rise to an AA'BB' spin system at low temperatures $(<260 \mathrm{~K})$, but only one signal is observed at $298 \mathrm{~K}$, indicating fast rotation of the ethylene ligand on the NMR timescale, see Figure 4 . Note that the ${ }^{195} \mathrm{Pt}$ satellites are observed at room temperature but are lost at lower temperatures, because of a larger chemical shift anisotropy contribution to relaxation. This phenomenon has also been observed for compound $\mathbf{2}$ (see supplemental figure S4).

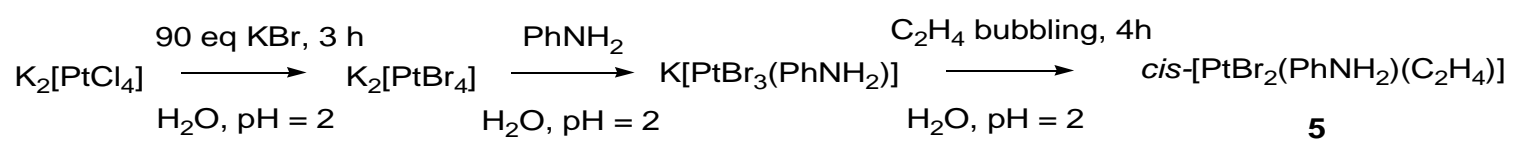

\section{Scheme 7.}

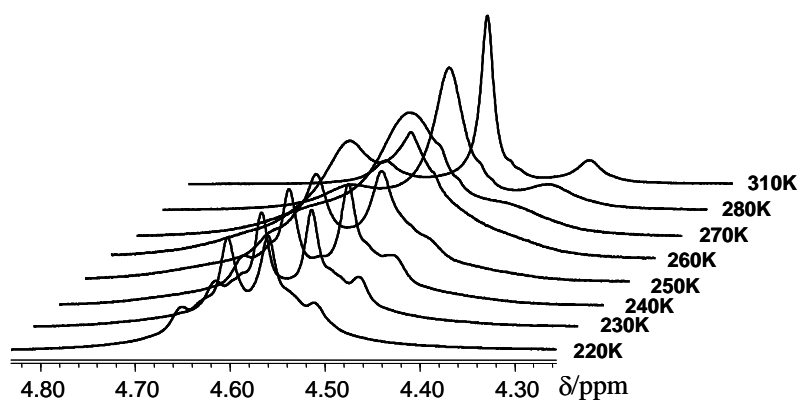

Figure 4. Variable temperature ${ }^{1} \mathrm{H}$ NMR spectrum of 5 in DMF- $d_{7}$.

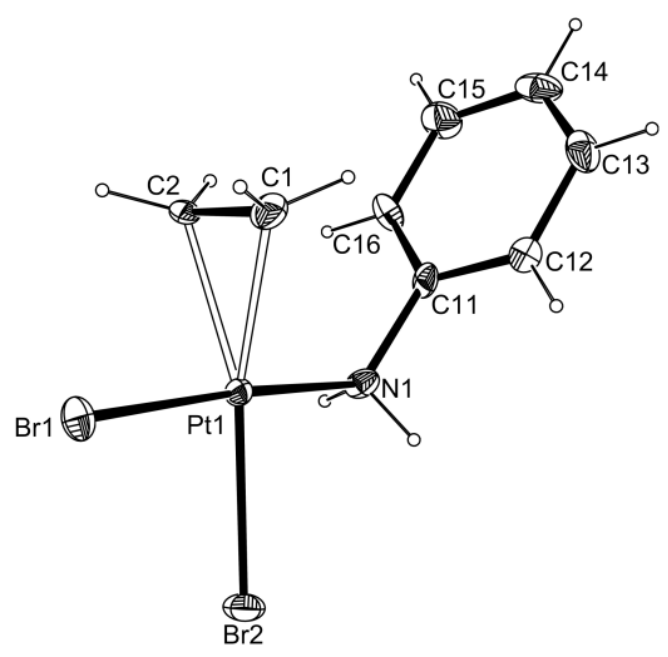


Figure 5. An ORTEP view of compound 5. Molecular ellipsoids are drawn at the $30 \%$ probability level. Selected bond distances (Å): Pt-Br1, 2.4239(13); Pt-Br2, 2.4364(13); Pt-N1, 2.082(10); Pt-C1, 2.112(13); Pt-C2, 2.130(12); C1-C2, 1.367(18).

A view of the molecular geometry, as determined by X-ray diffraction, is shown in Figure 5 with a selected list of bonding parameters. Additional bonding parameters are available in the Supporting Information (Table S6). Like for the trans isomer 4, compound 5 shows an extensive intermolecular $\mathrm{H}$-bonding network between the $\mathrm{Br}$ ligands and the aniline $\mathrm{NH}_{2}$ protons $(2.758$ and $2.848 \AA$ ) and also a contact between one of the $\mathrm{C}_{2} \mathrm{H}_{4}$ protons and a Br ligand $(2.882 \AA)$, see supplemental figure S3. There is apparently only one precedent for a cis- $\mathrm{PtBr}_{2}$ (alkene)(L) structure with an $\mathrm{N}$-donor ligand, namely cis- $\mathrm{PtBr}_{2}\left(\mathrm{C}_{2} \mathrm{H}_{4}\right) \mathrm{NH}_{3},{ }^{47}$ for which the Pt-N distance is reported as $2.13 \AA$ and the Pt-Br distances as 2.51 (trans to $\mathrm{C}_{2} \mathrm{H}_{4}$ ) and 2.40 (trans to $\mathrm{Br}$ ) $\AA$, the difference being attributed to trans effects. In compound $\mathbf{5}$, on the other hand, the difference between the two $\mathrm{Pt}-\mathrm{Br}$ distances is much less important. The $\mathrm{C}-\mathrm{C}$ distance is identical to those found in compounds $\mathbf{2}$ and $\mathbf{4}$ within the experimental error.

cis-[PtBr $\left.2\left(\mathbf{P h N H}_{2}\right)_{2}\right](6)$. In the course of this study, the previously reported ${ }^{48}$ compound $^{2}$ cis- $\left[\mathrm{PtBr}_{2}\left(\mathrm{PhNH}_{2}\right)_{2}\right]$ has also been obtained (94\% yield from $\mathrm{K}_{2} \mathrm{PtCl}_{4}$, see Scheme 8$)$. The purity was determined by elemental analysis and the configuration was confirmed by the X-ray structural analysis. The related cis- $\mathrm{PtCl}_{2}\left(\mathrm{PhNH}_{2}\right)_{2}$ complex was described as unstable in DMF, converting to the less soluble trans isomer which precipitates. ${ }^{49}$ In contrast, compound 6 shows stability in DMF- $d_{7}$ for at least 2 days, with only small intensity new resonances developing in the ${ }^{1} \mathrm{H}(\delta 5.20)$ and ${ }^{13} \mathrm{C}\left\{{ }^{1} \mathrm{H}\right\}(\delta 114.3)$ NMR spectra.

$\mathrm{K}_{2}\left[\mathrm{PtCl}_{4}\right] \stackrel{90 \text { eq } \mathrm{KBr}, 3 \mathrm{~h}}{\underset{\mathrm{H}_{2} \mathrm{O}}{\longrightarrow}} \mathrm{K}_{2}\left[\mathrm{PtBr}_{4}\right] \stackrel{\text { aniline, } 2 \text { eq }}{\underset{\mathrm{H}_{2} \mathrm{O}}{\longrightarrow}}$ cis- $\left[\mathrm{PtBr}_{2}(\mathrm{an})_{2}\right]$

6

\section{Scheme 8.}

The solid state structure of compound $\mathbf{6}$ has also been determined by X-ray crystallography, although the crystal quality did not allow a satisfactory data refinement. Nevertheless, the structural determination is sufficient to establish the chemical connectivity and molecular geometry, which is presented in Figure 6. The two cis aniline ligands adopt a conformation that places the two phenyl rings face to face. The same arrangement occurs intermolecularly, indicating a $\pi$-stacking interaction (see packing diagram in Figure S5). 


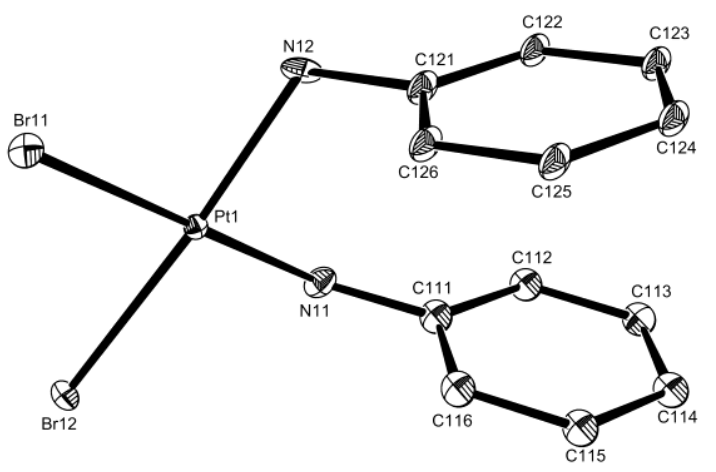

Figure 6. An ORTEP view of one of compound 6. Molecular ellipsoids are drawn at the $30 \%$ probability level.

\section{(b) Experimental studies of chemical equilibria.}

In order to evaluate the likely nature of the resting state of the $\mathrm{Pt}^{\mathrm{II}}$ hydroamination catalyst, various ligand exchange processes involving the synthesized complexes 1-6 were investigated. Accurate measurements of the equilibrium constants were not attempted because of a variety of technical difficulties (ethylene escapes into the gas phase, very slow equilibration times, ...), but the position of chemical equilibria could be qualitatively assessed in each case. Treating a solution of 2 with 8 equiv of $n \mathrm{Bu}_{4} \mathrm{PBr}$ in $\mathrm{CD}_{2} \mathrm{Cl}_{2}$ at $298 \mathrm{~K}$ yielded no immediate change. However, monitoring the intensity of the ${ }^{1} \mathrm{H}$ resonance of coordinated $\mathrm{C}_{2} \mathrm{H}_{4}$ revealed a slow decrease (ca. $18 \%$ after $2.5 \mathrm{~h} ; 20 \%$ after both $24 \mathrm{~h}$ and 4 days), indicating partial transformation to 1. A resonance for free $\mathrm{C}_{2} \mathrm{H}_{4}$ was not observed, probably because it escapes into the NMR tube head space. However, the presence of $\mathbf{1}$ was confirmed by its ${ }^{195} \mathrm{Pt}$-resonance. The formation of compound $\mathbf{1}$ from $\mathbf{2}$ and excess bromide was also indicated by the results of the synthetic studies: compound $\mathbf{1}$ contaminated $\mathbf{2}$ when this was prepared by halide exchange from Zeise's salt, unless operating under an ethylene atmosphere (vide supra, Scheme 4 and Scheme 6). These results suggest that the equilibrium of reaction 1 lies on the left hand side, even in the presence of excess $\mathrm{Br}^{-}$. This is likely to hold true under catalytic conditions (high $\mathrm{C}_{2} \mathrm{H}_{4}$ pressure, high $\mathrm{T}$ ), although the effect of $\mathrm{T}$ on the equilibrium has not been experimentally established.

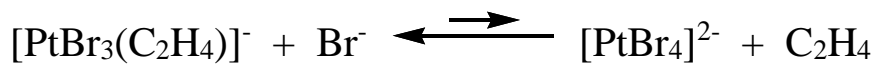


Addition of 8 equiv of $n \mathrm{Bu} 4 \mathrm{PBr}$ to complex 3 in $\mathrm{CD}_{2} \mathrm{Cl}_{2}$ at $298 \mathrm{~K}$ produces an upfield shift of the $o^{-}, m$ - and $p$ - $\mathrm{Ph}$ resonances, while the $\mathrm{NH}_{2}$ resonance slightly shifts downfield and decreases in relative intensity by $24 \%$. This behaviour is immediate and no further change occurs within the next few hours. The resonance shift may be attributed to the establishment of hydrogen bonding between the $\mathrm{NH}_{2}$ protons of the coordinated aniline ligand and free $\mathrm{Br}^{-}$. This interaction is expected to further polarize the N-H bond and deshield the proton. Similar effects of $\mathrm{H}$ bonding by $\mathrm{Br}^{-}$ligands on acidic proton resonances (for instance in imidazolium salts) have been previously observed. ${ }^{50}$ The presence of both free and coordinated aniline was confirmed by ${ }^{13} \mathrm{C}$ NMR. This experiment suggests that the equilibrium position of reaction 2 , like that of equation 1 , is shifted to the left hand side.

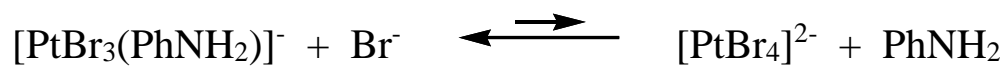
3

The above proposition was confirmed by studying the reaction in the opposite direction. Mixing compound 1 and $\mathrm{PhNH}_{2}$ (0.67 equiv) in $\mathrm{CD}_{2} \mathrm{Cl}_{2}$ shows no immediate change for the aniline peaks, while a precipitate (probably compound 6) starts to form in a few hours. In order to maintain a homogeneous system, thus obtaining more significant information on the reaction equilibrium and rate, the solvent was changed to DMF- $d_{7}$. Using a substoichiometric amount of $\mathrm{PhNH}_{2}$ (0.39 equiv) resulted in extensive but very slow consumption of the aniline (5\% after 25 h, $43 \%$ after 5.5 days) and formation of 3 . There was no evidence of precipitation, nor formation of any compound $\mathbf{6}$ in solution. Thus, it seems that the formation of $\mathbf{6}$ is only favoured in solvents in which it is insoluble. This proposition was confirmed by monitoring the reaction of $\mathbf{3}$ and $\mathrm{PhNH}_{2}$ (equation 3), as well as the reverse reaction between $\mathbf{6}$ and $n \mathrm{Bu} 4 \mathrm{PBr}$, in DMF- $d_{7}$. No change was observed in the spectrum of $\mathbf{3}+\mathrm{PhNH}_{2}(0.97$ equiv) after $17 \mathrm{~h}$ at room temperature, while the spectrum of $\mathbf{6}+n \mathrm{Bu} 4 \mathrm{PBr}(0.61$ equiv) showed the slow formation of 3 and free aniline ( 0.3 equiv after $23 \mathrm{~h}$ and complete reaction in 4 days). In conclusion, the reaction of $\mathbf{1}$ with aniline ( 1 equiv) to produce $\mathbf{3}$ is thermodynamically favoured under homogeneous conditions, but the further addition of a second equivalent of aniline to yield $\mathbf{6}$ is not. The relative stability of $\mathbf{2}$ and $\mathbf{3}$ in the presence of both aniline and ethylene cannot be probed directly, because the reactions of $\mathbf{2}$ with $\mathrm{PhNH}_{2}$ and of $\mathbf{3}$ with $\mathrm{C}_{2} \mathrm{H}_{4}$ yield the two isomeric neutral complexes $\left[\mathrm{PtBr}_{2}\left(\mathrm{C}_{2} \mathrm{H}_{4}\right)\left(\mathrm{PhNH}_{2}\right)\right]$.

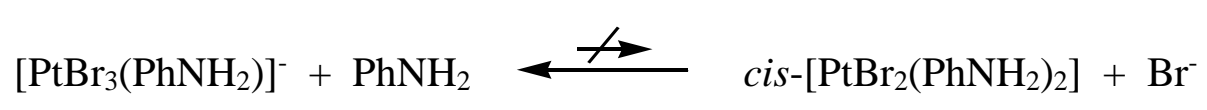


The next investigation was aimed at probing the relative thermodynamic stability of compounds 2,4 and 5, by examining the equilibrium position of the ligand exchange reactions 4 and 5. This study was carried out in $\mathrm{CD}_{2} \mathrm{Cl}_{2}$, THF- $d_{8}$ and DMF- $d_{7}$ at different temperatures, with ${ }^{1} \mathrm{H}$ NMR monitoring of the $\mathrm{C}_{2} \mathrm{H}_{4}$ and $\mathrm{PhNH}_{2}$ positions. DMSO- $d_{6}$ could not be used because of complications related to ligand exchange with solvent molecules, see Experimental section. Although compound 5 was obtained from 3 and $\mathrm{C}_{2} \mathrm{H}_{4}$ with release of $\mathrm{Br}^{-}$, the reverse reaction of 5 with $\mathrm{Br}^{-}$results in the substitution of aniline rather than ethylene.

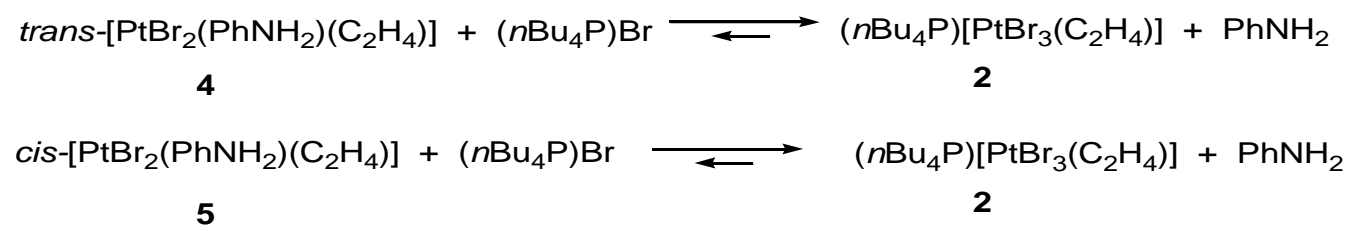

Reaction 4 was investigated at different molar ratios in both directions. The ligand exchange is fast, yielding equilibrium within the time needed to record the first spectrum for each experiment. Indeed, it is fast even on the NMR timescale above $200 \mathrm{~K}$, since only one $\mathrm{C}_{2} \mathrm{H}_{4}$ resonance ( $\delta$ range: 4.4-4.7 ppm) and one resonance for each type of aniline $\mathrm{NH}_{2}$ and ring proton ( $\delta$ range: $6.5-7.5 \mathrm{ppm}$ ) was observed, the position of which depends on the reagents ratio. Figure 7 shows an example in THF- $d_{8}$ at $298 \mathrm{~K}$. Related studies in $\mathrm{CD}_{2} \mathrm{Cl}_{2}$ are illustrated in the supporting information (Figure S6). Lowering the temperature slows down the ligand exchange and separate resonances can be observed for the ethylene resonances of the two Pt complexes at $\mathrm{T}<200 \mathrm{~K}$ (see supplemental Figure S7). Equilibrium could be conveniently approached from either side, because of the dominant trans effect of the ethylene ligand (formation of compound 5 was not observed in these solvents). The equilibrium position is heavily displaced toward the right hand side, since addition of $n \mathrm{Bu}_{4} \mathrm{PBr}$ to $\mathbf{4}$ gave an essentially quantitative transformation when using 1 equiv of the bromide salt or more. On the other hand, practically no change was observed upon mixing 2 with small amounts of aniline (1-2 equiv). Only after addition of a ca. 10 equiv of aniline could the formation of compound $\mathbf{4}$ became observable, as evidenced by a shift of the averaged $\mathrm{C}_{2} \mathrm{H}_{4}$ resonance. Unfortunately, the rapid exchange did not allow the observation of individual resonances for the accurate determination of the equilibrium parameters and use of the chemical shifts for the same determination was prevented by the chemical shift dependence on H-bonding. However, we can clearly conclude that equilibrium 4 
is strongly shifted toward the right hand side at room temperature in all solvents $\left(\mathrm{CD}_{2} \mathrm{Cl}_{2}\right.$, THF$d_{8}$ and DMF- $\left.d_{7}\right)$.

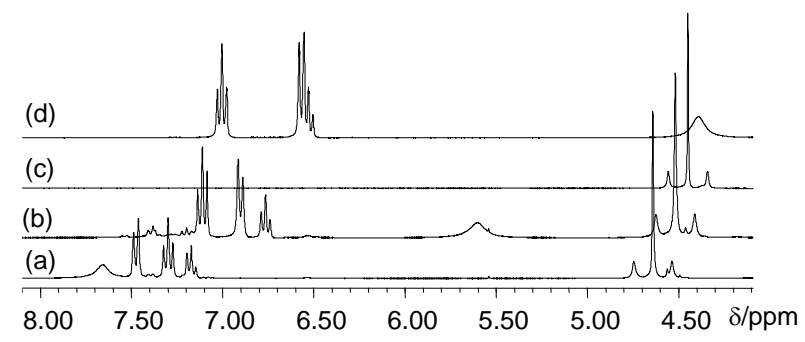

Figure 7. ${ }^{1} \mathrm{H}$ NMR spectra (olefin, $\mathrm{NH}_{2}$ and aromatic-region) of: a) $\mathbf{4}$; b) $\mathbf{4}$ in the presence of 0.72 equiv $n \mathrm{Bu} 4 \mathrm{PBr}$; c) 2 ; and d) aniline, in THF- $d_{8}$ at $298 \mathrm{~K}$. [4] $=[2]=0.5 \cdot\left[\mathrm{PhNH}_{2}\right]$ $=0.04 \mathrm{M}$.

Due to insolubility of compound $\mathbf{5}$ in dichloromethane and THF, the equilibrium study of reaction 5 was limited to DMF. This reaction is much slower than reaction 4, in agreement with the weaker trans effect of the $\mathrm{Br}$ ligand in 5 relative to the $\mathrm{C}_{2} \mathrm{H}_{4}$ ligand in $\mathbf{4}$. Thus, separated $\mathrm{C}_{2} \mathrm{H}_{4}$ resonances were observed for 5 and 2. Equilibration takes $>2$ days at room temperature starting from 5 and $n \mathrm{Bu} 4 \mathrm{PBr}$ (0.87 equiv) in DMF- $d_{7}$, see Figure 8 . Fitting as an equilibrium $1^{\text {st }}$ order kinetics gave $k=1.54(3) \cdot 10^{-5} \mathrm{~s}^{-1}$ and a $73 \%$ equilibrium molar fraction of compound 2 , showing that the equilibrium position of equation 5 lies on the right hand side like that of equation 4. No significant amount of isomer 4 forms during this process because of the small amount of released $\mathrm{PhNH}_{2}$ at equilibrium. Note that the $\mathrm{C}_{2} \mathrm{H}_{4}$ resonance of 5 moves downfield by ca. $0.1 \mathrm{ppm}$ upon introduction of $\mathrm{Br}^{-}$, but then moves back toward the position of pure $\mathbf{5}$ as the free $\mathrm{Br}^{-}$is progressively consumed. This effect is analogous to that described above for the $\mathrm{Br}^{-}$addition to $\mathbf{3}$ and is thus attributed to the same phenomenon, namely hydrogen bonding between free $\mathrm{Br}^{-}$and the $\mathrm{NH}_{2}$ protons of the coordinated aniline ligand. However, the effect in this case is transmitted through four bonds to the ethylene proton resonance. It is also possible that $\mathrm{Br}^{-}$establishes a direct interaction with the $\mathrm{C}_{2} \mathrm{H}_{4}$ protons. It was not possible to determine which equilibrium among 4 and 5 is shifted toward 2 to a greater extent. We can only conclude that the thermodynamic stability of the $5 / \mathrm{Br}^{-}$mixture is closer to that of the $4 / \mathrm{Br}^{-}$mixture than to that of the $2 / \mathrm{PhNH}_{2}$ mixture since both equilibria are largely displaced toward the right-hand side. 


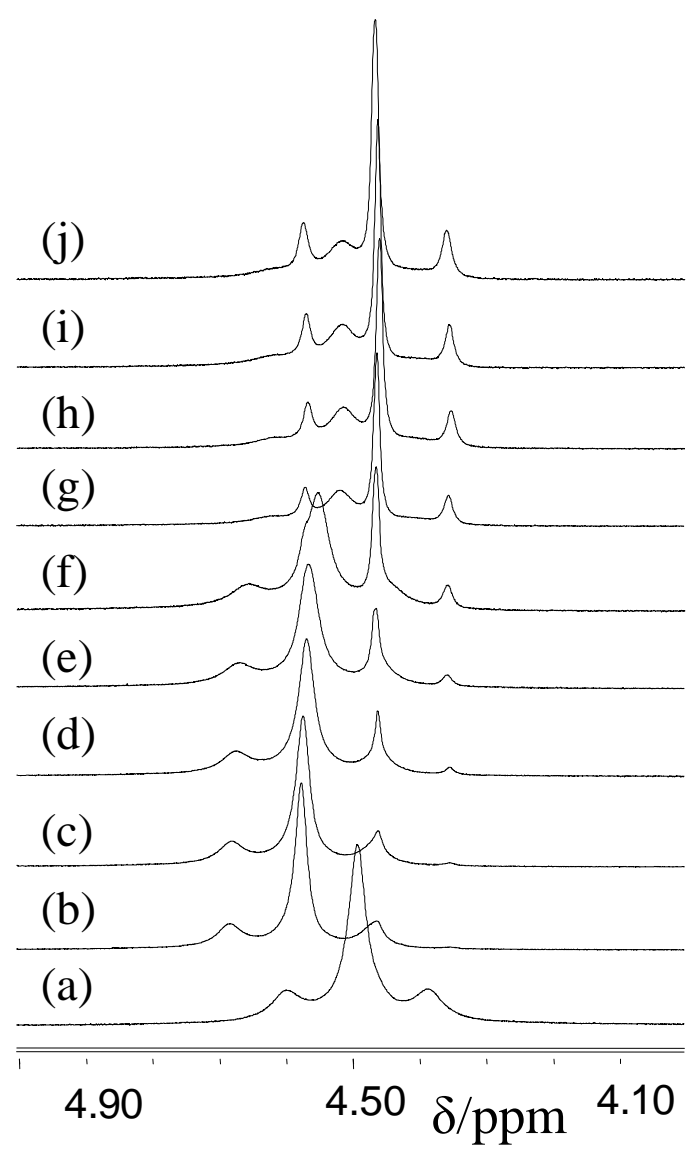

Figure 8. ${ }^{1} \mathrm{H}$ NMR spectra in DMF- $d_{7}$ at $298 \mathrm{~K}$ of: 5 (a); $5+n \mathrm{Bu}_{4} \mathrm{PBr}(0.87$ equiv) at 0 (b), 10 (c), 50 (d), 107 (e), $257 \mathrm{~min}(\mathrm{f}) ; 21.5$ (g) 24 (h), 28 (i), and 48 h (j).

The NMR observations above underline the strong effect of the ethylene ligand on the exchange rates at the trans position. Additional indication of this effect is hinted by the shape of the aniline $\mathrm{NH}_{2}$ resonance in the various compounds: the broadness of the resonance could also be related to a dynamic process involving exchange of the aniline acidic protons, but the presence of ${ }^{195} \mathrm{Pt}$ coupling for this resonance in compounds $\mathbf{3}$ and $\mathbf{5}$ and its absence in compound 4 strongly hints to a more rapid aniline ligand exchange in the latter compound as a result of the stronger ethylene trans effect. In order to verify this hypothesis, additional studies have been carried out by intentionally mixing additional aniline with the three above cited compounds. The result is the observation of separate resonances for free and coordinated $\mathrm{PhNH}_{2}$ when using compound $\mathbf{3}$ or $\mathbf{5}$, while only a single average resonance (the position of which depends on the $\mathrm{PhNH}_{2} / \mathrm{Pt}$ ratio) is observed for compound 4, see supplemental Figure S8. Cooling the solution broadens the aniline signal, but decoalescence is not observed in THF- $d_{8}$ down to $200 \mathrm{~K}$.

As mentioned in the introduction, a key step of the catalytic cycle is the amine nucleophilic addition to the coordinated alkene yielding a zwitterionic intermediate (6 or 8 in Scheme 1). Stable zwitterionic $\sigma$-alkyl complexes are formed by the addition of basic amines to coordinated ethylene in cis- or trans-[ $\left.\mathrm{Pt}\left(\mathrm{C}_{2} \mathrm{H}_{4}\right) \mathrm{Cl}_{2} \mathrm{~L}\right]$, for instance when using diethylamine, although these 
derivatives are often found to equilibrate with the amine/ethylene complex mixture in solution. ${ }^{51}$ The reaction products of eq 6 have been isolated and characterized by ${ }^{1} \mathrm{H}$ NMR spectroscopy ${ }^{51-57}$ and in one case by a single-crystal X-ray diffraction study. ${ }^{58}$ This reaction appears limited to amines of sufficient basicity $\left(\mathrm{pK}_{\mathrm{a}}>5\right.$ for the conjugate ammonium ion). For instance, aniline failed to give an observable addition compound ${ }^{53,} 54$ when reacted with trans$\left[\mathrm{Pt}\left(\mathrm{C}_{2} \mathrm{H}_{4}\right)\left(\mathrm{Et}_{2} \mathrm{NH}\right) \mathrm{Cl}_{2}\right]$.

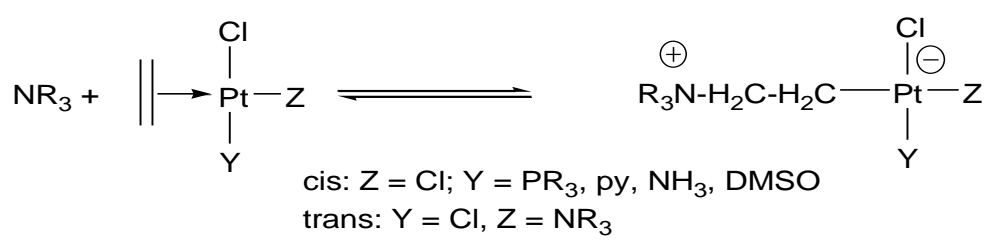

An NMR investigation of the interaction between 4 and 5 with $\mathrm{PhNH}_{2}$ was carried out in hope of observing the formation of the hydroamination product and perhaps also the putative zwitterionic $\mathrm{Pt}^{\mathrm{II}}$ or hydrido $\mathrm{Pt}^{\mathrm{IV}}$ intermediate (Scheme 1). The study was carried out in $\mathrm{CD}_{2} \mathrm{Cl}_{2}$, THF- $d_{8}$ and DMF- $d_{7}$ for compound 4 and only in DMF- $d_{7}$ for compound 5 for solubility reasons. In THF and $\mathrm{CD}_{2} \mathrm{Cl}_{2}$, compound 4 could be investigated up to the reflux temperature, whereas the studies in DMF- $d_{7}$ were limited to $298 \mathrm{~K}$ because extensive decomposition occurs at higher temperatures for both complexes. In the case of $\mathbf{4}$, the only observable phenomenon was the fast $\mathrm{PhNH}_{2}$ exchange already described above. No new resonance that could be attributed to a $\sigma$ alkyl complex or to the expected PhNHEt product was observed for either complex under any conditions. In conclusion, the activation barrier that must be overcome for the nucleophilic addition of $\mathrm{PhNH}_{2}$ to compounds $\mathbf{4}$ or $\mathbf{5}$ is such that no significant reaction occurs at the temperatures used for this study $\left(<68^{\circ} \mathrm{C}\right)$. Considering the NMR error (at least $1 \%$ reaction for detection), the time of the experiment $(1.5 \mathrm{~h})$ and the temperature, the activation free energy is estimated as $>29 \mathrm{kcal} \mathrm{mol}^{-1}$ at $68^{\circ} \mathrm{C}$ from the Eyring equation. The nucleophilic addition of aniline to complexes $\mathbf{2}, \mathbf{4}$ and $\mathbf{5}$ as well as all subsequent steps leading to the hydroamination product and to the catalyst regeneration have been investigated computationally and will be reported in a forthcoming separate contribution.

\section{(c) Ethylene hydroamination by aniline with complexes 2, 4 and 5 as catalysts.}

In order to verify that the ethylene-containing complexes $\mathbf{2}, \mathbf{4}$ and $\mathbf{5}$ are possible intermediates of the catalytic cycle, we checked whether they are able to catalyze the hydroamination of ethylene by aniline under the same conditions previously reported ${ }^{1}$ for $\mathrm{PtBr}_{2}$ and whether they provide similar results in terms of activity and selectivity (refer to Scheme 9). 
The results are shown in Table 3. It can be seen that all compounds yield the main hydroamination product, $N$-ethyl aniline, with TON in the range 75-100 under the same experimental conditions. Similar selectivities are also found with the various compounds. The catalytic tests with $\mathrm{PtBr}_{2}$ have also been repeated and found to yield results consistent with those previously reported. ${ }^{1}$ Since no significant difference was observed by reducing the amount of $n \mathrm{Bu}_{4} \mathrm{PBr}$ to only a tenfold excess, all subsequent runs were carried out with the lower bromide salt amount.

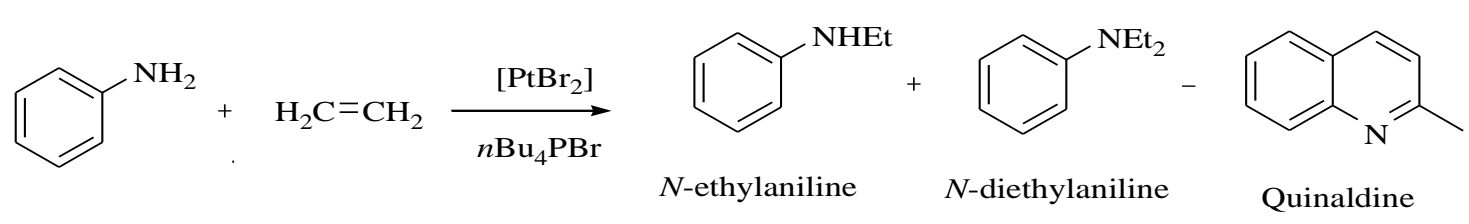

\section{Scheme 9.}

Table 3. Catalytic results for the aniline addition to ethylene with compounds $\mathrm{PtBr}_{2}, 2,4$ and 5 in the presence of $n \mathrm{Bu}_{4} \mathrm{PBr}^{\text {a }}$

\begin{tabular}{ccccc}
\hline$[\mathrm{Pt}]$ & Salt (eq) & $\begin{array}{c}\text { PhNHEt } \\
\text { TON }\end{array}$ & $\begin{array}{c}\mathrm{PhNEt}_{2} \\
\text { TON }\end{array}$ & $\begin{array}{c}\text { Quinaldine } \\
\text { TON }\end{array}$ \\
\hline $\mathrm{PtBr}_{2}$ & ${ }^{n} \mathrm{Bu}_{4} \mathrm{PBr}(150)^{\mathrm{b}}$ & 100 & 2 & 4 \\
$\mathrm{PtBr}_{2}$ & ${ }^{n} \mathrm{Bu}_{4} \mathrm{PBr}(10)^{\mathrm{b}}$ & 100 & 4 & 12 \\
$\mathbf{2}$ & ${ }^{n} \mathrm{Bu} 4 \mathrm{PBr}(10)$ & 75 & 2 & 15 \\
$\mathbf{4}$ & ${ }^{n} \mathrm{Bu} 4 \mathrm{PBr}(10)$ & 70 & 5 & 8 \\
$\mathbf{5}$ & ${ }^{n} \mathrm{Bu}_{4} \mathrm{PBr}(10)$ & 91 & 12 & 8 \\
\hline
\end{tabular}

${ }^{\mathrm{a}} \mathrm{T}=150^{\circ} \mathrm{C}, \mathrm{t}=10 \mathrm{~h} ; \mathrm{p}\left(\mathrm{C}_{2} \mathrm{H}_{4}\right)=25$ bars. ${ }^{\mathrm{b}}$ Results very close to those previously reported under identical conditions.

The results of Table 3 confirm that complexes 2, $\mathbf{4}$ and $\mathbf{5}$ are competent precatalysts and suggest that they all yield the same catalytic system obtained from $\mathrm{PtBr}_{2}$. According to the proposed catalytic cycle (Scheme 1) and as shown by our synthetic work, these complexes can be readily formed under catalytic conditions. Since the rate determining step of the hydroamination process is probably a later step according to Scheme 1 (e.g. the nucleophilic aniline addition to coordinated ethylene, or the elimination of the hydroamination product), ${ }^{5}$ the transition state of which is at higher energy than those associated to the formation of $\mathbf{2 , 4}$ and $\mathbf{5}$, all these complexes should be in equilibrium with each other under the catalytic conditions and should therefore in principle yield the same catalytic activity.

\section{(d) DFT calculations}


The geometry optimizations were carried out in the gas phase. The gas-phase thermochemical data, which included the full thermal correction to the gas phase Gibbs free energy, ${ }^{59}$ were then corrected by solvation effects in aniline and in dichloromethane, using the results of C-PCM calculations on the fixed gas-phase geometries. Dichloromethane was chosen in order to compare the computational results with the experimental equilibrium studies described in section (b), most of which were conducted in that solvent. Aniline was also used because the hydroamination catalysis is conducted in the absence of solvent, thus the substrate itself (aniline) provides the reaction medium for dissolution of all metal complexes. The polarity of the medium may be significantly altered by the dissolved ionic co-catalyst, $n \mathrm{Bu}_{4} \mathrm{PBr}$, but no simple method is available to include this effect in the calculations to the best of our knowledge. The relative free energies in aniline solution were also calculated at $423.15 \mathrm{~K}$, temperature at which the catalytic experiments were carried out. Since the translational and rotational contributions are significantly quenched upon going from the gas phase to the solution, we also derived relative free energy values using only the vibrational contribution of the entropy as a corrective term. ${ }^{60}$ These values, however, are less in agreement with the experimental data and will only be given and briefly discussed in the SI.

A full list of computed gas-phase energies and free energies, and solvation free energies in dichloromethane and aniline is available as Supporting Information (Table S8). All computed systems are labelled with Roman numerals, with the numeric value corresponding to that of the isolated compound (for instance, the $\left[\mathrm{PtBr}_{4}\right]^{2-}$ ion of compound $\mathbf{1}$ is given label $\mathbf{I}$, the $\left[\operatorname{PtBr}_{3}\left(\mathrm{C}_{2} \mathrm{H}_{4}\right)\right]^{-}$ion of compound $\mathbf{2}$ is labelled as $\mathbf{I I}$, etc.). The calculations also addressed the possible formation of bis(ethylene) complexes, trans-[ $\left.\mathrm{PtBr}_{2}\left(\mathrm{C}_{2} \mathrm{H}_{4}\right)_{2}\right]$ (two isomers, VII and VII') and cis-[ $\left.\mathrm{PtBr}_{2}\left(\mathrm{C}_{2} \mathrm{H}_{4}\right)_{2}\right]$ (VIII). These are not known compounds, but the corresponding cis$\left[\mathrm{PtCl}_{2}\left(\mathrm{C}_{2} \mathrm{H}_{4}\right)_{2}\right]$ has recently been isolated and crystallographically characterized, ${ }^{61}$ whereas the trans isomer does not appear to be a stable complex. ${ }^{61-63}$ It is interesting to verify whether the relative energy of these complexes is sufficiently low to warrant their consideration as potential intermediates in the catalytic cycle.

The relevant optimized geometrical parameters of the platinum complexes I' and II-V and views of the optimized geometries are shown next to the related experimental X-ray data in the Supporting Information section (Tables S2-S7). There is generally good agreement between experimental and calculated data, with all distances being slightly overestimated by the calculations as typically found for DFT calculation with hybrid functionals. The discrepancy is highest for the Pt-Br distances and strongest in the dianion $(2.527 \AA$ vs. an average of $2.424 \AA$ or $\Delta=+0.103 \AA$ for I) and slightly smaller in the monoanions $(\Delta=+0.074$ for II, +0.049 for III), and in the neutral species $(\Delta=+0.068$ for $\mathbf{I V},+0.035$ for $\mathbf{V})$. The neglect of the counterion in the 
calculation of the ionic species is probably not responsible for this discrepancy, because strong ion pairing is expected to lengthen, not shorten, bond distances. The calculations confirm the absence of a notable trans influence of $\mathrm{C}_{2} \mathrm{H}_{4}$ relative to $\mathrm{Br}$ on the $\mathrm{Pt}-\mathrm{Br}$ distance, whereas the $\mathrm{Pt}$ Br bond is slightly shorter (by ca. $0.04 \AA$ ) when located trans to aniline in complexes III, V and VI. The Pt-N bond is also little affected by the nature of the trans ligand $\left(\mathrm{Br}\right.$ or $\mathrm{C}_{2} \mathrm{H}_{4}$; maximum differences of $0.03 \AA$ ). The trend of the ethylene C-C distance is interesting $(1.398 \AA$ in $\mathbf{I V}$, 1.404 in $\mathbf{V}, 1.408 \AA$ in II), because it suggests a $\pi$ back-bonding trend in the order IV $<$ V $<$ II. This distance variation is too small to be experimentally revealed by the X-ray technique for compounds $\mathbf{4}, \mathbf{5}$ and $\mathbf{2}$, but is consistent with the observed shift of the $v(C=C)$ vibration. Thus, 4 should be the most reactive of these three compounds toward nucleophilic attack by external aniline. The geometry of VI differs from that found in the solid state in that the $\mathrm{Ph}$ rings of the two different aniline ligands are located on opposite sides of the coordination plane. This energy minimum is also obtained when using the solid state geometry as input. This result suggests that the observed solid state geometry is enforced by the intermolecular $\pi$-stacking interactions.

The geometry of the bis(ethylene) adducts was optimized as both trans and cis isomers. Although the introduction of a second ethylene molecule to complex II would be directed to the trans position by the trans effect of the first ethylene ligand, a subsequent isomerization may occur as recently shown for the dichlorido analogue. ${ }^{61}$ For the trans complex, two different configurations were probed, the first one having both ethylene $\mathrm{C}-\mathrm{C}$ bonds perpendicular to the coordination plane (VII) and the second one with one perpendicular and one parallel C-C bond (VII'). The relative energy of VII' is, as expected, higher than that of VII. Thus, only the bis(perpendicular) arrangement (experimentally observed for the dichlorido analogue) was calculated for the cis isomer VIII. In system VII the C-C distance is shorter (1.382 $\AA$ ) than in systems II, IV and $\mathbf{V}$, since the two $\mathrm{C}_{2} \mathrm{H}_{4}$ ligands are in mutual competition for electron density through $\mathrm{Pt}_{-} \mathrm{C}_{2} \mathrm{H}_{4}$ back-bonding. The distance in the cis isomer VIII is longer (1.395 $\left.\mathrm{\AA}\right)$, though still marginally shorter that in IV. In system VII' the ethylene ligand with the perpendicular C-C bond is more strongly affected by back-bonding (C-C: $1.397 \AA$, about the same as in IV), whereas the parallel ethylene ligand is very weakly bonded to $\mathrm{Pt}(\mathrm{Pt}-\mathrm{C}=2.331 \AA$, vs. 2.195 for the perpendicular ligand) and the C-C distance is much shorter (1.372 $\AA$ ), though still significantly lengthened relative to free ethylene $[1.330 \AA, c f$. the experimental value of $\left.1.3391(13)^{64}\right]$. The reduced back-bonding in these ligands, while the $\mathrm{C}_{2} \mathrm{H}_{4}-\mathrm{Pt}$ dative interaction is still effective, makes them also interesting candidates for a nucleophilic attack by external amine. 
Table 4. Relative free energy values (in $\mathrm{kcal} \mathrm{mol}^{-1}$ ) of systems I-VIII. The values shown take into account the addition and subtraction of ligands from system $\mathbf{I}$. $^{\mathrm{a}}$

\begin{tabular}{cccc}
\hline System & $\Delta \mathrm{G}_{\mathrm{DCM}, 298.15}$ & $\Delta \mathrm{G}_{\text {aniline, } 298.15}$ & $\Delta \mathrm{G}_{\text {aniline,423.15 }}$ \\
\hline I & 0.0 & 0.0 & 0.0 \\
I' & -7.6 & -9.1 & -10.9 \\
II & -11.4 & -14.6 & -14.5 \\
III & -6.7 & -8.7 & -9.6 \\
IV & -8.0 & -10.7 & -9.7 \\
V & -6.0 & -8.4 & -7.4 \\
VI & -1.6 & -2.9 & -1.0 \\
VII & 0.2 & -3.2 & -2.6 \\
VII' & 5.5 & 1.8 & 1.8 \\
VIII & -1.9 & -5.3 & -5.0 \\
\hline
\end{tabular}

The relative energies of systems I-VIII are given in Table 4. There is little difference between the results in aniline and dichloromethane solution, all relative $G$ values being slightly less negative (or more positive) in dichloromethane. This is probably related to the greater ability of dichloromethane to solvate charged species $(\varepsilon=8.93)$ relative to aniline $(\varepsilon=6.89)$, thus having a greater bias in favour of $\left[\mathrm{PtBr}_{4}\right]^{2-}$. Solvation (Table S8) increases in the order: neutral species (IV, V, VI, VII, VII', VIII, $\mathrm{C}_{2} \mathrm{H}_{4}, \mathrm{PhNH}_{2}$ ) < monoanions (II, III, Br-) < dianion (I). Note that all systems are more stable than I, except for VII' which is ca. $5 \mathrm{kcal} \mathrm{mol}^{-1}$ less stable than its isomer VII. The absence of the counterion in the calculations may disfavour the ionic species relative to the neutral ones, since ion pairing is expected to provide a slight energetic stabilization to the system. This means that in reality species II may be even more stabilized, relative to the neutral species IV, V, VI, VII and VIII, than shown by the values in Table 4 . Note that the relative free energies in solution experience minor changes on going from room temperature to $150^{\circ} \mathrm{C}$ (temperature of the catalytic runs) and the situation remains qualitatively the same. Under all conditions, the species with the lowest free energy in solution is II. This system is thus the most likely candidate as catalyst resting state. All these species are relatively close in energy and much lower than the transition state leading to the hydroamination product (estimated as $>29 \mathrm{kcal} \mathrm{mol}^{-1}$ relative to $\mathbf{I I}$ at $68^{\circ} \mathrm{C}$, vide supra). Consequently, they can all be considered to be present either as intermediates or as off-loop equilibrium species under catalytic conditions.

\section{Discussion}

The main interest of this investigation was to throw more light onto the mechanism of the recently reported hydroamination of ethylene by aniline catalyzed by ligandless $\mathrm{PtBr}_{2}$, upon activation by $n \mathrm{Bu}_{4} \mathrm{PBr}$. What we have learned is that all the isolated compounds 1-6, and even 
the bis(ethylene) complexes trans- $\mathrm{PtBr}_{2}\left(\mathrm{C}_{2} \mathrm{H}_{4}\right), 7$, and cis- $\mathrm{PtBr}_{2}\left(\mathrm{C}_{2} \mathrm{H}_{4}\right)_{2}, \mathbf{8}$, are likely to exist, in equilibrium with each other, under catalytic conditions. Only the trans isomer of the mixed ethylene-aniline complex $\left[\mathrm{PtBr}_{2}\left(\mathrm{PhNH}_{2}\right)\left(\mathrm{C}_{2} \mathrm{H}_{4}\right)\right]$ (4) was previously proposed as intermediate. The major species in solution (catalyst resting state), however, is likely to be $\left[\mathrm{PtBr}_{3}\left(\mathrm{C}_{2} \mathrm{H}_{4}\right)\right]^{-}$, so far as a sufficient pressure of $\mathrm{C}_{2} \mathrm{H}_{4}$ is present. Thus, the initial part of the catalytic cycle can be revised as shown in Scheme 10. All the ethylene-containing complexes (II, IV, V, VII, VII' and VIII) may be susceptible to nucleophilic attack by aniline. Using the Boltzmann distribution and the values in Table 4, the relative amounts of the ethylene-containing species at $150^{\circ} \mathrm{C}$ may be estimated as II/IV/V/VII/VII'/VIII = $1: 3.3 \cdot 10^{-3}: 2.2 \cdot 10^{-4}: 7.2 \cdot 10^{-7}: 3.9 \cdot 10^{-9}: 1.3 \cdot 10^{-5}$. In spite of the small equilibrium amount estimated for many of these species, they must all be considered as potential substrates for the nucleophilic attack by aniline in the subsequent elementary step because a higher energy (and thus less populated) species may lead to a lower barrier for the rate determining step of the catalytic cycle. Investigations on these subsequent steps are currently ongoing and will be reported in a forthcoming contribution.

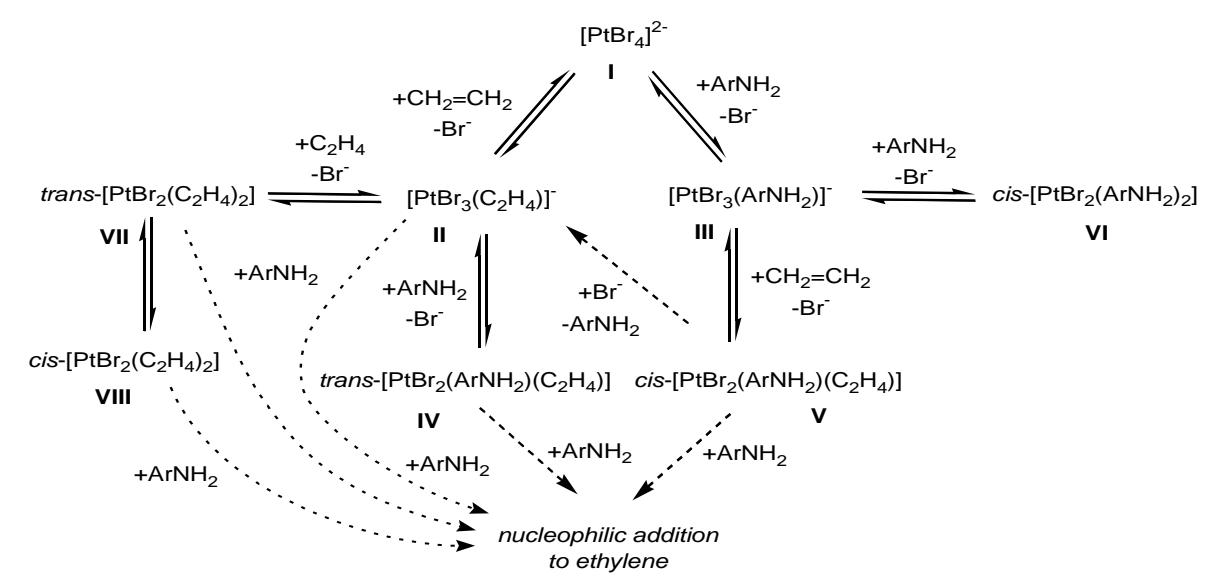

Scheme 10. Revised mechanism for the hydroamination of ethylene by aniline.

An important point is the qualitative agreement between the experimental results of the equilibrium studies and the computational results, provided that the free energies in solutions are used. Precise calibration of the theoretical method is not possible because we could not obtain accurate equilibrium constants for the various ligand exchange processes (Equations 1-5). However, all observations are qualitative reproduced by the computational study. Namely, the conversion of $\mathbf{I}$ into I' and $\mathrm{Br}^{-}$is spontaneous (though slow). The higher free energy of $\mathbf{I}$ ' and $\mathrm{C}_{2} \mathrm{H}_{4}$ relative to II agrees with the literature report that $\left[\mathrm{Pt}_{2} \mathrm{Br}_{6}\right]^{2-}$ transforms into $\left[\mathrm{PtBr}_{3}\left(\mathrm{C}_{2} \mathrm{H}_{4}\right)\right]^{-}$ upon addition of ethylene. ${ }^{65}$ The relative $\mathrm{G}$ values of $\mathbf{I I} / \mathrm{Br}^{-}$and $\mathbf{I I I} / \mathrm{Br}^{-}$agree with the displacement of equilibria 1 and 2 to the left hand side. The $\mathrm{G}$ value of $\mathbf{V I} / \mathrm{Br}^{-}$relative to III/PhNH 2 agrees with the displacement of equilibrium 3 to the left hand side (the opposite 
process is driven by the precipitation of $\mathbf{6})$. Furthermore, $\mathbf{I I}\left(+\mathrm{PhNH}_{2}\right)$ is also thermodynamically preferred relative to $\mathbf{I V}$ and $\mathbf{V}\left(+\mathrm{Br}^{-}\right)$, in agreement with equilibria 4 and 5 being displaced to the right hand side. According to the calculation, the trans complex IV is more stable than its cis isomer V. Finally, the lower energy of VIII relative to VII qualitatively agrees with the spontaneous trans to cis isomerization of the analogous $\mathrm{PtCl}_{2}\left(\mathrm{C}_{2} \mathrm{H}_{4}\right)_{2}$ complex. ${ }^{61}$ Given the general agreement between theory and experiment, this computational level appears suitable to further investigate the subsequent steps of the catalytic cycle, for which no experimental information is available.

\section{Conclusion}

This contribution provides straightforward procedures for the one-pot synthesis of several $\mathrm{Pt}^{\mathrm{II}}$ bromido derivatives, some previously reported, others described here for the first time. The work described in this contribution has also served to clarify a few important points of the ethylene hydroamination process catalyzed by the $\mathrm{PtBr}_{2} / n \mathrm{Bu}_{4} \mathrm{PBr}$ system. A greater number of ethylene complexes than previously imagined are found as likely candidates for the crucial aniline nucleophilic addition step. A rich $\mathrm{Pt}^{\mathrm{II}}$ coordination chemistry in the presence of bromide, ethylene and aniline ligands has been unveiled and all the isolated complexes are suggested by the DFT study to be viable intermediates or equilibrium off-loop species of the catalytic cycle. The general agreement between the DFT results (in terms of free energy changes in solution) and the experimental equilibrium studies encourages us to pursue our DFT exploration of the remainder of the catalytic cycle.

\section{Experimental part.}

General. The ethanol used as reaction solvent was of $95 \%$ grade and water was deionized. All other solvents were of HPLC grade and were used as received. Aniline (Fluka) was distilled under vacuum and kept under argon in the dark. $\mathrm{K}_{2} \mathrm{PtCl}_{4}(\mathrm{Strem})$ and $\mathrm{K}\left[\mathrm{PtCl}_{3}\left(\mathrm{C}_{2} \mathrm{H}_{4}\right)\right] \cdot \mathrm{H}_{2} \mathrm{O}$ (Aldrich) were used as received. $n \mathrm{Bu}_{4} \mathrm{PBr}$ (Aldrich) was stored in a desiccator under vacuum. Ethylene (purity $\geq 99.5 \%$ ) was purchased from Air Liquide.

Instrumentation. NMR investigations were carried out on a Bruker DPX300 spectrometer operating at $300.1 \mathrm{MHz}\left({ }^{1} \mathrm{H}\right), 121.49 \mathrm{MHz}\left({ }^{31} \mathrm{P}\right), 75.47 \mathrm{MHz}\left({ }^{13} \mathrm{C}\right)$ and $64.5 \mathrm{MHz}\left({ }^{195} \mathrm{Pt}\right)$. The spectra were calibrated with the residual solvent resonance relative to TMS $\left({ }^{1} \mathrm{H},{ }^{13} \mathrm{C}\right)$ and with external 85\% $\mathrm{H}_{3} \mathrm{PO}_{4}\left({ }^{31} \mathrm{P}\right)$ and $\mathrm{Na}_{2} \mathrm{PtCl}_{6}\left({ }^{195} \mathrm{Pt}\right)$. IR spectra (neat/4000-600 $\left.\mathrm{cm}^{-1}\right)$ were recorded on a Perkin-Elmer Spectrum 100 FTIR spectrometer $\left(2 \mathrm{~cm}^{-1}\right.$ resolution). UV measurements were 
recorded on a Varian Cary $50 \mathrm{WinUV}$ or on a PerkinElmer Lambda $35 \mathrm{UV} /$ vis spectrometer using $\mathrm{CaF}_{2}$ cells of $1 \mathrm{~cm}$ path length. Elemental analyses were performed by the Microanalytical Service of the Laboratoire de Chimie de Coordination. The capillaries charged with the compounds for the melting points were sealed before measuring. For all compounds, the physical (color, melting point) and microanalytical data $(\mathrm{C}, \mathrm{H}, \mathrm{N})$ are reported in Table 1, whereas the NMR properties in $\mathrm{CD}_{2} \mathrm{Cl}_{2}\left({ }^{195} \mathrm{Pt},{ }^{1} \mathrm{H}\right.$ and $\left.{ }^{13} \mathrm{C}\left\{{ }^{1} \mathrm{H}\right\}\right)$ are listed in Table 2. Other characterization data (NMR in other solvents, UV-visible, IR) are given in the Supporting Information. More detailed analyses of vibrational coupling in compounds 1-6 on the basis of IR and Raman studies are published elsewhere. ${ }^{25}$

${ }^{195} \mathrm{Pt}$ NMR study of equilibrium between $\mathrm{K}_{2} \mathrm{PtCl}_{4}$ and $\mathrm{KBr}$. To a water solution ( $\left.3 \mathrm{~mL}\right)$ of $\mathrm{K}_{2} \mathrm{PtCl}_{4}(55 \mathrm{mg})$ was added $\mathrm{KBr}(0.79$ or $1.26 \mathrm{~g} ; 50$ or 80 equiv) and the obtained mixture was stirred at room temperature for several days. The equilibrium was checked by transferring aliquots of the solution into an NMR tube charged with ca. $100 \mu \mathrm{L}$ of $\mathrm{D}_{2} \mathrm{O}$ for lock and measured by ${ }^{195} \mathrm{Pt}$ NMR spectroscopy (30000 scans). The spectra showed two resonances at $-2367\left\{\left[\mathrm{PtBr}_{3} \mathrm{Cl}\right]^{2-}\right\}$ and $-2662 \mathrm{ppm}\left\{\left[\mathrm{PtBr}_{4}\right]^{2-}\right\}$ with intensity peak ratios of $1: 22$ or 1:33, respectively, at equilibrium (the signal to noise ratio for the smaller peak is 4).

Preparation of $\left(n \mathrm{Bu}_{4} \mathrm{P}\right)\left[\mathrm{PtCl}_{3}\left(\mathrm{C}_{2} \mathrm{H}_{4}\right)\right]$ (2-Cl). To a saturated $\mathrm{KCl}$ aqueous solution $(3 \mathrm{~mL})$ was added $\mathrm{K}\left[\mathrm{PtCl}_{3}\left(\mathrm{C}_{2} \mathrm{H}_{4}\right)\right] \cdot \mathrm{H}_{2} \mathrm{O}(30 \mathrm{mg}, 0.078 \mathrm{mmol})$ and a solution of $n \mathrm{Bu} 4 \mathrm{PBr}(28 \mathrm{mg}, 0.083$ mmol) in $\mathrm{CH}_{2} \mathrm{Cl}_{2}(2 \mathrm{~mL})$. The resulting two-phase system was intensively stirred over $10 \mathrm{~min}$, then the organic phase was recovered and the solvent was evaporated and the resulting residue was dried under vacuum for $2 \mathrm{~h}$. The yield of product after solvent evaporation was $40 \mathrm{mg}$ $(88 \%)$.

Synthesis of $\left(\boldsymbol{n B u} \mathbf{B u}_{4}\right)_{2}\left[\mathbf{P t B r}_{4}\right](\mathbf{1})$. To a solution of $\mathrm{K}_{2} \mathrm{PtCl}_{4}(107 \mathrm{mg}, 0.258 \mathrm{mmol})$ in water (5 mL) was added $\mathrm{KBr}(2.76 \mathrm{~g}, 90$ equiv) and the resulting solution was stirred at room temperature for 3 hours. It was then transferred into a separating funnel and intensively shaken with a solution of $n \mathrm{Bu} 4 \mathrm{PBr}\left(175 \mathrm{mg}, 2\right.$ equiv) in $6 \mathrm{~mL}$ of $\mathrm{CH}_{2} \mathrm{Cl}_{2}$. Since the resulting mixture was a relatively stable emulsion, 3 additional $\mathrm{mL}$ of water were added and the mixture was shaken again, resulting in the rapid separation of two clear phases. The organic layer was collected and shaken two more times with distilled water ( $8 \mathrm{~mL}$ each time). The organic layer was then evaporated to dryness and the brown-light residue was dried in vacuo for 20 min, then washed with pentane $(5 \mathrm{~mL})$ and finally dried in vacuo over $\mathrm{P}_{4} \mathrm{O}_{10}$ overnight. Yield: $181 \mathrm{mg}$ $(68 \%)$.

Synthesis of $\left(n \mathrm{Bu}_{4} \mathrm{P}\right)\left[\mathrm{PtBr}_{3}\left(\mathrm{C}_{2} \mathrm{H}_{4}\right)\right]$ (2). Method A. From Zeise's salt. An aqueous solution $(5 \mathrm{~mL})$ of $\mathrm{K}\left[\mathrm{PtCl}_{3}\left(\mathrm{C}_{2} \mathrm{H}_{4}\right)\right] \cdot \mathrm{H}_{2} \mathrm{O}(100 \mathrm{mg}, 0.271 \mathrm{mmol})$ and $\mathrm{KBr}(1.61 \mathrm{~g}, 50$ equiv) was stirred under a continuous ethene flushing for 20 hours at room temperature. After this time the 
solution was transferred into a separating funnel where it was intensively shaken with a solution of $n \mathrm{Bu}_{4} \mathrm{PBr}(92 \mathrm{mg}, 0.271 \mathrm{mmol})$ in $\mathrm{CH}_{2} \mathrm{Cl}_{2}(5 \mathrm{~mL})$. Since the resulting mixture was a relatively stable emulsion, 3 additional $\mathrm{mL}$ of water were added and the mixture was shaken again, resulting in the rapid separation of two clear phases. Yellow-orange crystals of pure $\left(n \mathrm{Bu}_{4} \mathrm{P}\right)\left[\mathrm{PtBr}_{3}\left(\mathrm{C}_{2} \mathrm{H}_{4}\right)\right]$ were obtained after separation of the organic phase, solvent evaporation and recrystallization of the residue from dichloromethane/diethyl ether. Yield: $120 \mathrm{mg}(61 \%)$. The complex immediately and quantitatively reacts with DMSO- $d_{6}$, yielding a yellow solution characterized by a single ${ }^{195} \mathrm{Pt}$ resonance at $\delta-3578\left(\mathrm{~s}, \Delta v_{1 / 2}=21 \mathrm{~Hz}, 298 \mathrm{~K}\right)$. The formation of free ethylene is witnessed by the ${ }^{1} \mathrm{H}$ (singlet at $\delta$ 5.42) and ${ }^{13} \mathrm{C}\left\{{ }^{1} \mathrm{H}\right\}$ (singlet at $\delta$ 124.0) resonances. These observation suggest the formation of complex $\left[\mathrm{PtBr}_{3}\left(\mathrm{DMSO}-d_{6}\right)\right]^{-}$.

Method B. From K2PtCl . To a solution of $\mathrm{K}_{2} \mathrm{PtCl}_{4}(200 \mathrm{mg}, 0.482 \mathrm{mmol})$ in water (8 $\mathrm{mL}$ ) was added 90 equiv $\mathrm{KBr}(5.16 \mathrm{~g})$ and the obtained solution was stirred for 3 hours at room temperature. The solvent was then evaporated under vacuum and $\mathrm{K}_{2} \mathrm{PtBr}_{4}$ was extracted by three portions (ca. $10 \mathrm{ml})$ of a EtOH/HBr $(30 \mathrm{~mL}+2 \mathrm{~mL})$ mixture and filtered through Celite. Ethene gas was flushed through the obtained solution during 4 hours, then $n \mathrm{Bu} 4 \mathrm{PBr}(163 \mathrm{mg}, 0.482$ mmol) was added and the resulting mixture was stirred under an ethene flush for 1 hour. The pure yellow-orange $\left(n \mathrm{Bu}_{4} \mathrm{P}\right)\left[\mathrm{PtBr}_{3}\left(\mathrm{C}_{2} \mathrm{H}_{4}\right)\right]$ was obtained after solvent evaporation, washing with water $(4 \times 6 \mathrm{ml})$, recrystallization from dichloromethane/diethyl ether, washing with pentane and finally drying in vacuo. Yield: $160 \mathrm{mg}(46 \%)$. The spectroscopic data of this material were identical to those of the product of method A.

Synthesis of ( $\boldsymbol{n B u} 4 \mathbf{P})\left[\mathbf{P t B r}_{3}\left(\mathbf{P h N H}_{2}\right)\right]$ (3). To a solution of $\mathrm{K}_{2} \mathrm{PtCl}_{4}(260 \mathrm{mg}, 0.626 \mathrm{mmol})$ in water $(12 \mathrm{~mL})$, adjusted to $\mathrm{pH}=2$ by addition of $\mathrm{CH}_{3} \mathrm{COOH}$, was added $\mathrm{KBr}(6.71 \mathrm{~g}, 90$ equiv) and the resulting mixture was stirred for $3 \mathrm{~h}$ at room temperature. Aniline ( $57 \mu \mathrm{L}, 0.626$ $\mathrm{mmol}$ ) in $0.5 \mathrm{~mL}$ of EtOH was then added drop by drop and the obtained mixture was stirred for $1 \mathrm{~h}$, resulting in the formation of a yellow-orange precipitate. To this mixture was added a solution of $n \mathrm{Bu}_{4} \mathrm{PBr}(212 \mathrm{mg}, 0.626 \mathrm{mmol})$ in dichloromethane $(7 \mathrm{~mL})$ and the resulting biphasic system was vigorously stirred for $20 \mathrm{~min}$, transferred into the separating funnel, and the red organic phase was separated. Following solvent evaporation and recrystallization from dichloromethane/diethyl ether, red crystals of pure $(n \mathrm{Bu} 4 \mathrm{P})\left[\mathrm{PtBr}_{3}\left(\mathrm{PhNH}_{2}\right)\right]$ were obtained in $41 \%$ yield (202 mg).

Synthesis of trans-PtBr2 $\left(\mathrm{PhNH}_{2}\right)\left(\mathrm{C}_{2} \mathrm{H}_{4}\right)$ (4). Method A. From $\mathrm{K}_{2} \mathrm{PtCl}_{4}$. To an aqueous solution (6 mL) of $\mathrm{K}_{2} \mathrm{PtCl}_{4}(100 \mathrm{mg}, 0.241 \mathrm{mmol})$ was added $\mathrm{KBr}(2.580 \mathrm{~g}$, 90 equiv) and the resulting solution was stirred for $3 \mathrm{~h}$ at room temperature. The solvent was then evaporated under reduced pressure and $\mathrm{K}_{2} \mathrm{PtBr}_{4}$ was extracted by three equal portions of a $\mathrm{EtOH} / \mathrm{HBr}$ mixture (total volume: $15 \mathrm{~mL} \mathrm{EtOH}+1 \mathrm{~mL}$ conc. aqueous $\mathrm{HBr}$ ) and filtered through Celite. The 
resulting solution was flushed with ethylene for $5 \mathrm{~h}$, then the solvent was evaporated to dryness. Dissolution in water $(7 \mathrm{~mL})$ followed by addition of an ethanol solution of aniline $(22 \mu \mathrm{L}, 0.241$ $\mathrm{mmol}$ in $0.5 \mathrm{~mL}$ ) resulted in an immediate precipitation of a yellow powder. After $1 \mathrm{~h}$ of stirring, the solid was filtered, washed with water and dried. It was then redissolved in the minimum amount of dichloromethane (ca. $3 \mathrm{~mL}$ ) and the solution was filtered and evaporated to dryness. Yield: $49 \%$ (56 mg). The compound is unstable in DMSO- $d_{6}$, yielding a mixture of products $\left({ }^{195} \mathrm{Pt}\right.$ resonances at $\delta-3306,-3495,-3578,-3733$ with approximate relative ratio of 1:6:1:3 from signal integration). The resonance at $\delta-3578$ is identical to that obtained by dissolution of 2 and tentatively assigned to $\left[\mathrm{PtBr}_{3}\left(\mathrm{DMSO}-d_{6}\right)\right]^{-}$(see above). The compound slowly changes color toward black when kept in air for several days as a solid. Storage under argon is recommended.

Method B. From Zeise's salt. An aqueous solution ( $8 \mathrm{~mL}$ ) of Zeise's salt (200 mg, 0.543 mmol) and $\mathrm{KBr}$ (3.228 g, 50 equiv) was stirred under an ethene flush for $20 \mathrm{~h}$ at room temperature. An aniline $(50 \mu \mathrm{L}, 0.543 \mathrm{mmol})$ solution in $\mathrm{EtOH}(1 \mathrm{ml})$ was then added dropwise, yielding a yellow precipitate. After stirring for $1 \mathrm{~h}$ at room temperature, the precipitate was filtered, washed with water and dried in vacuo. Subsequent washing with pentane and drying in vacuo affords yellow trans-[ $\left.\mathrm{PtBr}_{2}\left(\mathrm{C}_{2} \mathrm{H}_{4}\right)\left(\mathrm{PhNH}_{2}\right)\right]$ in $73 \%$ yield $(189 \mathrm{mg})$. The spectroscopic data of this material were identical to those of the product of method A.

Synthesis of cis-PtBr2 $\left(\mathrm{PhNH}_{2}\right)\left(\mathrm{C}_{2} \mathrm{H}_{4}\right)(5)$, from $\mathrm{K}_{2} \mathrm{PtCl}_{4}$. To an aqueous solution $(5 \mathrm{~mL})$ of $\mathrm{K}_{2} \mathrm{PtCl}_{4}$ (100 mg, $0.241 \mathrm{mmol}$ ), adjusted to $\mathrm{pH}=2$ by the addition of $\mathrm{CH}_{3} \mathrm{COOH}$, was added $\mathrm{KBr}(2.58 \mathrm{~g}, 90$ equiv) and the resulting mixture was stirred for $3 \mathrm{~h}$ at room temperature. Aniline $(22 \mu \mathrm{L}, 0.241 \mathrm{mmol}$ ) in $0.5 \mathrm{~mL}$ of $\mathrm{EtOH}$ was then added dropwise and the resulting mixture was stirred for $1 \mathrm{~h}$, yielding a small amount of yellow precipitate. After filtration, the resulting red solution was flushed with ethene for $4 \mathrm{~h}$ yielding a yellow-green precipitate, which was then filtered. The precipitate was washed with water and dried in vacuo. Yield: $48 \mathrm{mg}$ (42\%).

Synthesis of cis-PtBr2 $\left(\mathbf{P h N H}_{2}\right)_{2}$ (6). To a solution of $\mathrm{K}_{2} \mathrm{PtCl}_{4}(1000 \mathrm{mg}, 2.409 \mathrm{mmol})$ in water $(40 \mathrm{~mL})$ was added $\mathrm{KBr}(25.8 \mathrm{~g}, 90$ equiv) and the resulting mixture was stirred for $3 \mathrm{~h}$ at room temperature. A solution of aniline $(440 \mu \mathrm{L}, 4.818 \mathrm{mmol})$ in $2 \mathrm{~mL}$ of EtOH was then added dropwise. The mixture was stirred for $3 \mathrm{~h}$ and filtered. The pale yellow precipitate was washed sequentially with water, $\mathrm{EtOH}$, and $\mathrm{Et}_{2} \mathrm{O}$ and then dried in vacuo. Yield: $1.23 \mathrm{~g}$ (94\%). The compound is not stable in DMSO. Upon dissolving the compound in DMSO- $d_{6}$, the formation of new ${ }^{195} \mathrm{Pt}$ NMR resonances (a major peak at $\delta-3495$ and a minor one at $\delta-3306$ ) was observed. They are tentatively attributed to $\left[\mathrm{PtBr}_{2}(\mathrm{DMSO})\left(\mathrm{PhNH}_{2}\right)\right]$ and $\left[\mathrm{PtBr}_{2}(\mathrm{DMSO})_{2}\right]$, respectively.

X-Ray crystallography. Single crystals of 1, 2 and $\mathbf{3}$ suitable for the X-ray study were prepared as follows: to a suspension of the compound in $\mathrm{Et}_{2} \mathrm{O}$ at the reflux temperature was added dichloromethane dropwise until a homogenous system formed. The solution was then 
filtered while hot and kept at $-20^{\circ} \mathrm{C}$ overnight. In the case of $\mathbf{1}$, the solution was then further concentrated to approximately $1 / 3$ of its original volume and kept at $-20^{\circ} \mathrm{C}$ during two weeks, yielding large (ca. $3 \mathrm{~mm}$ ) deep-red crystals. Crystals of $\mathbf{4}$ were prepared in the same manner as $\mathbf{2}$ and 3, albeit using a pentane/Et ${ }_{2} \mathrm{O}$ combination. The crystals of $\mathbf{5}$ were prepared by slow evaporation of a saturated acetone solution. A single crystal of each compound was mounted under inert perfluoropolyether on the tip of a glass fiber and cooled in the cryostream of a Bruker APEX2 CCD diffractometer. Data were collected using the monochromatic MoK $\alpha$ radiation $(\lambda=$ 0.71073). The structures were solved by direct methods (SIR97) ${ }^{66}$ and refined by least-squares procedures on $F^{2}$ using SHELXL-97. ${ }^{67}$ All $\mathrm{H}$ atoms attached to carbon were introduced in calculation in idealized positions and treated as riding models. The drawing of the molecules was realised with the help of ORTEP $32 .{ }^{68}$ Crystal data and refinement parameters are given in the supporting information (Table S10). Crystallographic data (excluding structure factors) have been deposited with the Cambridge Crystallographic Data Centre as supplementary publication no. CCDC 725742 - 725747. Copies of the data can be obtained free of charge on application to the Director, CCDC, 12 Union Road, Cambridge CB2 1EZ, UK (fax: (+44) 1223-336-033; email: deposit@ccdc.cam.ac.uk).

Computational Details. All geometry optimizations were performed with the Gaussian03 suite of programs ${ }^{69}$ using the B3LYP functional which includes the three-parameter gradientcorrected exchange functional of Becke ${ }^{70}$ and the correlation functional of Lee, Yang, and Parr which includes both local and non-local terms. ${ }^{71,72}$ The basis set chosen was the standard 6$31+\mathrm{G}^{*}$, which includes both polarization and diffuse functions that are necessary to allow angular and radial flexibility to the highly anionic systems, for all atoms of type $\mathrm{H}, \mathrm{C}, \mathrm{N}$, and $\mathrm{Br}$. The Pt atom was described by the LANL2TZ(f) basis, which is an uncontracted version of LANL2DZ and includes an f polarization function and an ECP. ${ }^{73}$ The starting geometries for the calculations where derived from the solid state X-ray structure, whenever available, or adapted from those by appropriate ligand substitution (specifically for systems VII and expected VIII). For the ionic species, the calculations were carried out on the free ion, without consideration of ion pair formation with the counterion. Frequency calculations were carried out for all optimized geometries in order to verify their nature as local minima and for the calculation of thermodynamic parameters at 298.15 and at $423.15 \mathrm{~K}$ under the gas-phase and harmonic approximations. Solvent effects were included by means of CPCM single point calculations on the gas-phase optimized geometries. ${ }^{74,} 75$ Thus, the solution free energy was calculated as $\Delta \mathrm{H}_{\text {gas }}+\mathrm{T} \Delta \mathrm{S}_{\mathrm{gas}}+\Delta \mathrm{G}^{\mathrm{CPCM}}$, the corrective term $\Delta \mathrm{G}^{\mathrm{CPCM}}$ being indicated as $\Delta \mathrm{G}_{\text {solv }}$ by the Gaussian program. 
Acknowledgement. We thank the CNRS and the RFBR for support through a France-Russia (RFBR - CNRS) bilateral grant № 08-03-92506, and the MENESR (Ministère de l'Éducation nationale de l'enseignement supérieur et de la recherche de France) for a Ph.D. fellowship to PD. 


\section{References}

$1 \quad$ Brunet, J. J.; Cadena, M.; Chu, N. C.; Diallo, O.; Jacob, K.; Mothes, E., Organometallics 2004, 23, 1264-1268.

Brunet, J. J.; Chu, N. C.; Diallo, O., Organometallics 2005, 24, 3104-3110.

Rodriguez-Zubiri, M.; Anguille, S.; Brunet, J.-J., J. Mol. Catal. A 2007, 271, 145-150.

Brunet, J.-J.; Chu, N.-C.; Rodriguez-Zubiri, M., Eur. J. Inorg. Chem. 2007, 4711-4722.

Senn, H. M.; Blochl, P. E.; Togni, A., J. Am. Chem. Soc. 2000, 122, 4098-4107.

Wang, X.; Widenhoefer, R. A., Organometallics 2004, 23, 1649-1651.

Footnote1.

Shagisultanova, G. A., Zh. Neorg. Khim. 1961, 6, 1771-1773.

Lyashenko, M. N., Trudy Inst. Krist., Akad. Nauk S.S.S.R. 1954, 9, 335-348.

Shubochkin, L. K.; Gushchin, V. I., Zh. Neorg. Khim. 1973, 18, 3257-3259.

Bagnoli, F.; Dell'amico, D. B.; Calderazzo, F.; Englert, U.; Marchetti, F.; Merigo, A.;

Ramello, S., J. Organomet. Chem. 2001, 622, 180-189.

Melanson, R.; Rochon, F. D.; Hubert, J., Acta Crystallogr., Sect. B 1979, B35, 736-8.

Kroening, R. F.; Rush, R. M.; Martin, D. S., Jr.; Clardy, J. C., Inorg. Chem. 1974, 13, 13661373.

Peters, T. J.; Kroening, R. F.; Martin, D. S., Jr., Inorg. Chem. 1978, 17, 2302-2307.

Stephenson, N. C., Acta Crystallogr. 1964, 17, 587-91.

Russell, D. R.; Tucker, P. A.; Whittaker, C., Acta Crystallogr., Sect. B: Struct. Sci. 1975, 31, 2530-2531.

Chojnacki, C., Jahresber. 1870, 510.

Anderson, J. S., J. Chem. Soc. 1934, 971-3.

Derenzi, A.; Diblasio, B.; Saporito, A.; Scalone, M.; Vitagliano, A., Inorg. Chem. 1980, 19, 960-966.

Pesa, F.; Spaulding, L.; Orchin, M., J. Coord. Chem. 1975, 4, 225-230.

Mink, J.; Papai, I.; Gal, M.; Goggin, P. L., Pure Appl. Chem. 1989, 61, 973-978.

Powell, D. B.; Scott, J. G. V.; Sheppard, N., Spectrochim. Acta, Part A 1972, 28, 327-35.

Jobic, H., J. Mol. Struct. 1985, 131, 167-175.

Nakamoto, K., Infrared and Raman Spectra of Inorganic and Coordination Compounds, Part B, $5^{\text {th }}$ Edition. ed.; John Wiley \& Sons Inc.: New York, 1997.

Dub, P. A.; Filippov, O. A.; Belkova, N. V.; Rodriguez-Zubiri, M.; Poli, R., J. Phys. Chem. A 2009, 113, 6348-6355.

Bonner, L. G., J. Am. Chem. Soc. 1936, 58, 34-39.

Bokii, G. B.; Kukina, G. A., Zh. Strukt. Khim. 1965, 6, 706-715.

Wunderlich, J. A.; Mellor, D. P., Acta Cryst. 1954, 7, 130.

Wunderlich, J. A.; Mellor, D. P., Acta Cryst. 1955, 8, 57.

Bokii, G. B.; Kukina, G. A., Kristallografiya 1957, 2, 400-407.

Black, M.; Mais, R. H. B.; Owston, P. G., Acta Crystallogr., Sect. B 1969, 25, 1753-1759.

Love, R. A.; Koetzle, T. F.; Williams, G. J. B.; Andrews, L. C.; Bau, R., Inorg. Chem. 1975, $14,2653-2657$.

Rochon, F. D.; Bonnier, C., Inorg. Chim. Acta 2007, 360, 461-472.

Muir, M. M.; Gomez, G. M.; Muir, J. A., Acta Crystallogr., Sect. C: Cryst. Struct. Commun. 1986, 42, 1699-1701.

Muir, J. A.; Gomez, G. M.; Muir, M. M.; Cox, O.; Cadiz, M. E., Acta Crystallogr., Sect. C: Cryst. Struct. Commun. 1987, 43, 1258-1261.

Ruiz, E.; Tang, X. J.; Li, Y. J.; Muir, M. M., J. Cryst. Spectr. Res. 1993, 23, 791-794.

Muir, M. M.; Gomez, G. M.; Cadiz, M. E.; Muir, J. A., Inorg. Chim. Acta 1990, 168, 47-57.

Gomez, G. M.; Muir, M. M.; Muir, J. A.; Cox, O., Acta Crystallogr., Sect. C: Cryst. Struct.

Commun. 1988, 44, 1554-1557.

Lozano, C. M.; Muir, M. M.; Tang, X. J.; Li, Y. J., J. Chem. Crystall. 1994, 24, 639-642. 
Foulds, G. A.; Hall, P. S.; Thornton, D. A., J. Mol. Struct. 1984, 117, 95-101.

Heyde, T.; Foulds, G. A.; Thornton, D. A.; Desseyn, H. O.; Vanderveken, B. J., J. Mol.

Struct. 1983, 98, 11-18.

Pesa, F.; Orchin, M., J. Organomet. Chem. 1974, 78, C26-C28.

Pesa, F.; Orchin, M., Inorg. Chem. 1975, 14, 994-996.

Caruso, F.; Spagna, R.; Zambonelli, L., Inorg. Chim. Acta 1979, 32, L23-L24.

Merlino, S.; Lazzaroni, R.; Montagnoli, G., J. Organometal. Chem. 1971, 30, C93-C95.

Footnote2.

Kukina, G. A.; Bokii, G. B.; Brusentsev, F. A., Zh. Strukt. Khim. 1964, 5;7, 30-6.

Auf Der Heyde, T. P. E.; Foulds, G. A.; Thornton, D. A.; Watkins, G. M., J. Mol. Struct. 1981, 77, 19-24.

Kong, P. C.; Rochon, F. D., Inorg. Chim. Acta 1982, 61, 269-71.

Wolf, J.; Labande, A.; Daran, J.-C.; Poli, R., Eur. J. Inorg. Chem. 2008, 3024-3030.

Sarhan, J. K. K.; Green, M.; Al-Najjar, I. M., J. Chem. Soc., Dalton Trans. 1984, 771-777.

Kaplan, P. D.; Schmidt, P.; Orchin, M., J. Amer. Chem. Soc. 1968, 90, 4175-4176.

Panunzi, A.; De Renzi, A.; Palumbo, R.; Paiaro, G., J. Amer. Chem. Soc. 1969, 91, 38793883.

Hollings, D.; Green, M.; Claridge, D. V., J. Organometal. Chem. 1973, 54, 399-402.

Pesa, F.; Orchin, M., J. Organomet. Chem. 1976, 108, 135-8.

Al-Najjar, I. M.; Green, M., J. Chem. Soc., Chem. Commun. 1977, 926-927.

Pryadun, R.; Sukumaran, D.; Bogadi, R.; Atwood, J. D., J. Am. Chem. Soc. 2004, 126, 12414-12420.

Benedetti, E.; De Renzi, A.; Paiaro, G.; Panunzi, A.; Pedone, C., Gazz. Chim. Ital. 1972, 102, 744-54.

Braga, A. A. C.; Ujaque, G.; Maseras, F., Organometallics 2006, 25, 3647-3658.

Sumimoto, M.; Iwane, N.; Takahama, T.; Sakaki, S., J. Am. Chem. Soc. 2004, 126, $10457-$ 10471.

Otto, S.; Roodt, A.; Elding, L. I., Inorg. Chem. Commun. 2006, 9, 764-766.

Chatt, J.; Wilkins, R. G., Nature (London, U. K.) 1950, 165, 859-60.

Plutino, M. R.; Otto, S.; Roodt, A.; Elding, L. I., Inorg. Chem. 1999, 38, 1233-1238.

Hirota, E.; Endo, Y.; Saito, S.; Yoshida, K.; Yamaguchi, I.; Machida, K., J. Mol.

Spectroscopy 1981, 89, 223-231.

Muir, M. M.; Cancio, E. M., Inorg. Chim. Acta 1970, 565-7.

Altomare, A.; Burla, M.; Camalli, M.; Cascarano, G.; Giacovazzo, C.; Guagliardi, A.;

Moliterni, A.; Polidori, G.; Spagna, R., J. Appl. Cryst. 1999, 32, 115-119.

Sheldrick, G. M., SHELXL97. Program for Crystal Structure refinement. ed.; University of Göttingen: Göttingen, Germany, 1997.

Farrugia, L. J., J. Appl. Crystallogr. 1997, 32, 565.

M. J. Frisch, G. W. T., H. B. Schlegel, G. E. Scuseria, M. A. Robb, J. R. Cheeseman, J.

Montgomery, J. A., T. Vreven, K. N. Kudin, J. C. Burant, J. M. Millam, S. S. Iyengar, J.

Tomasi, V. Barone, B. Mennucci, M. Cossi, G. Scalmani, N. Rega, G. A. Petersson, H.

Nakatsuji, M. Hada, M. Ehara, K. Toyota, R. Fukuda, J. Hasegawa, M. Ishida, T. Nakajima,

Y. Honda, O. Kitao, H. Nakai, M. Klene, X. Li, J. E. Knox, H. P. Hratchian, J. B. Cross, C.

Adamo, J. Jaramillo, R. Gomperts, R. E. Stratmann, O. Yazyev, A. J. Austin, R. Cammi, C.

Pomelli, J. W. Ochterski, P. Y. Ayala, K. Morokuma, G. A. Voth, P. Salvador, J. J.

Dannenberg, V. G. Zakrzewski, S. Dapprich, A. D. Daniels, M. C. Strain, O. Farkas, D. K. Malick, A. D. Rabuck, K. Raghavachari, J. B. Foresman, J. V. Ortiz, Q. Cui, A. G. Baboul, S. Clifford, J. Cioslowski, B. B. Stefanov, G. Liu, A. Liashenko, P. Piskorz, I. Komaromi, R. L. Martin, D. J. Fox, T. Keith, M. A. Al-Laham, C. Y. Peng, A. Nanayakkara, M.

Challacombe, P. M. W. Gill, B. Johnson, W. Chen, M. W. Wong, C. Gonzalez, J. A. Pople,, Gaussian 03, Revision C.02, Gaussian, Inc., Wallingford CT 2004.

Becke, A. D., J. Chem. Phys. 1993, 98, 5648-5652. 
Lee, C. T.; Yang, W. T.; Parr, R. G., Phys. Rev. B 1988, 37, 785-789.

Miehlich, B.; Savin, A.; Stoll, H.; Preuss, H., Chem. Phys. Lett. 1989, 157, 200-206.

Roy, L. E.; Hay, P. J.; Martin, R. L., J. Chem. Theory Comput. 2008, 4, 1029-1031.

Barone, V.; Cossi, M., J. Phys. Chem. A 1998, 102, 1995-2001.

75

Cossi, M.; Rega, N.; Scalmani, G.; Barone, V., J. Comput. Chem. 2003, 24, 669-681. 


\section{ToC Text and Graphics}

Solution equilibria between various $\mathrm{PtBr}_{2}$ derivatives containing $\mathrm{C}_{2} \mathrm{H}_{2}$ and $\mathrm{PhNH}_{2}$ have been assessed experimental and computationally in reference to the $\mathrm{PtBr}_{2} / \mathrm{Br}^{-}$-catalyzed hydroamination of ethylene by aniline.
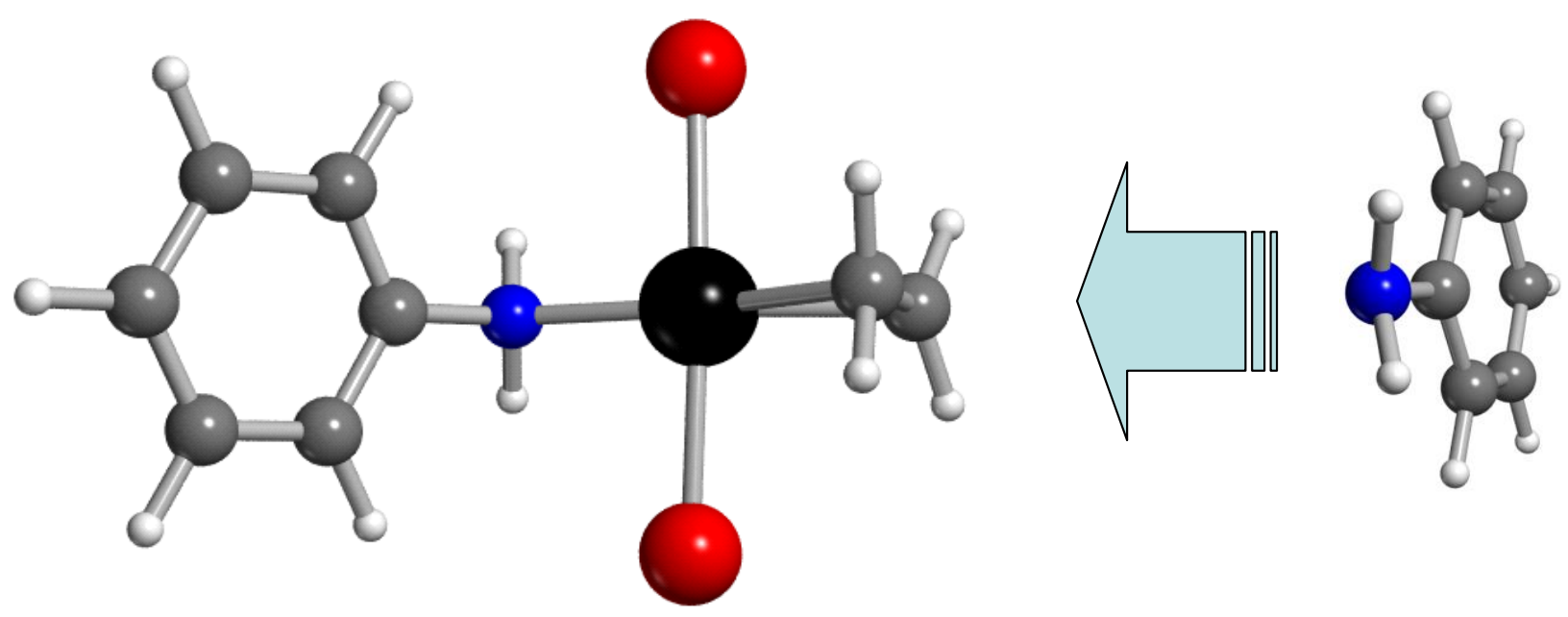